\title{
Photonic and nanobiophotonic properties of luminescent lanthanide-doped hybrid organic-inorganic materials
}

\author{
Purificación Escribano, ${ }^{* a}$ Beatriz Julián-López, ${ }^{a}$ José Planelles-Aragó, ${ }^{a}$ Eloisa Cordoncillo, ${ }^{a}$ Bruno Viana ${ }^{b}$ \\ and Clément Sanchez ${ }^{* b}$
}

Received 16th July 2007, Accepted 12th October 2007

First published as an Advance Article on the web 6th November 2007

DOI: $10.1039 / \mathrm{b} 710800 \mathrm{a}$

\begin{abstract}
Research into lanthanide-doped organic-inorganic hybrid materials emerged in the 1990s with the development of interesting materials for optics: high efficiency and stable solid-state lasers, new fiber amplifiers and sensors, devices with upconversion, fast photochromic and non-linear responses, etc. Their interest relies on the possibility of combining properties of sol-gel host materials (shaping, tunable refractive index and mechanical properties, corrosion protection, specific adhesion, etc.) and the well-known luminescence of lanthanide ions (Ln). The fast development of photonic hybrids allowed the commercial exploitation of products with new or enhanced characteristics (megajoule pulsed Nd-YAG laser, protective coatings of glasses, screens or glasswares). However, recently, Ln-hybrid nanocomposites have found new applications in bio-sensors, bio-analytics and even clinical imaging diagnostics. These applications make use of the fluorescence properties of lanthanides that make luminescent hybrids ideal candidates for time-resolved fluoroimmunoassays, DNA hybridation assays, fluorescence imaging microscopy, or in vivo imaging. As a consequence, the goal of this review is twofold: (i) as a reminder of some general considerations that must be taken into account to design new optically active Ln-doped nanocomposites whatever the application field, and (ii) to show the most important advances achieved in the past years in different areas, paying special attention to bio-medical applications.
\end{abstract}

\footnotetext{
${ }^{a}$ Departamento de Química Inorgánica y Orgánica, Universitat Jaume I, Avda. Sos Baynat s/n, 12071, Castellón, Spain.

E-mail: escriban@qio.uji.es; Fax:+34 964 728214; Tel: +34 964728247 ${ }^{b}$ Laboratoire de Chimie de la Matière Condensée de Paris, UMR-CNRS 7574, Université Pierre et Marie Curie, 4 place Jussieu, 75252 Paris, France.E-mail: clems@ccr.jussieu.fr; Fax: +33 144274769; Tel: +33144275534
}

\section{Introduction: how and why Ln-doped hybrid materials become good candidates for advanced optical applications}

Optical communication technology is one of the marvels of modern technological achievements. It showcases the fact that photons are far better suited than electrons to fast

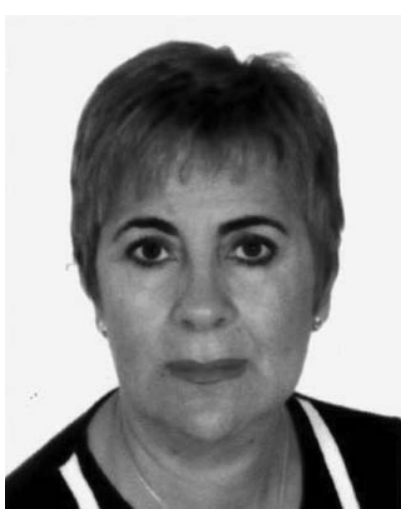

Purificación Escribano
Prof. Purificación Escribano, has more than 20 years experience in applied materials research. She received her PhD in 1982 in Inorganic Chemistry, at University of Valencia. She is Full Professor of Inorganic Chemistry and leads a research group at Jaume I University of Castellon (Spain). Her interests include the synthesis, characterization and application of ceramic pigments with low environmental impact by using lanthanide ions and soft chemistry routes to prepare tailored hybrid organic-inorganic nanomaterials with interesting optical properties. She is the co-author of over 130 scientific publications of strong impact, book chapters and proceedings.

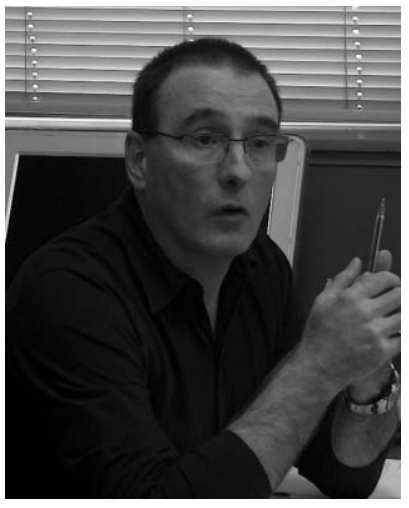

Clément Sanchez is Director of Research at the CNRS, head of laboratory named "Chimie de la Matière Condensée de Paris" and head of the Nanochemistry Division of C'Nano IDF. His field of research concerns the designed construction of inorganic and hybrid organic-inorganic nanomaterials for applications associated with domains such as: environment, energy, optics and health. His work encompasses investigations that span areas of soft chemistry, bio-inspired

Clément Sanchez approaches to hierarchically structured materials, templated synthesis of porous and non-porous materials. He is the co-author of over 300 scientific publications in scientific journals of strong impact and he has presented over 100 invited lectures in international conferences. He belongs to the Thomson Scientific's ISIHighlyCited.list that highlight the world's most cited authors from the last two decades across diverse disciplines. 
communication. Several developments in the late 1960s and early 1970s led to the original fiber optic system that has since evolved into today's high-speed networks that can transmit information at amazing speeds. Beyond communications, photonics are already finding new applications in aerospace, sensing, lighting, computing and medical areas.

Photonic devices are fabricated from a variety of materials, although semiconductors and glasses are the two major constituents for making the core components. The lasers and the detectors are almost exclusively made from semiconductors and offer remarkable performance in wavelength precision and sensitivity. Silica glasses serve as the basis for fiber-based devices and have also been the preferred materials for planar lightware circuits (PLCs), although new materials are needed to fully exploit the deep potential of optical circuits. Polymers have been used for both fiber and planar devices but suffer from uncertainties about their long term reliability and performance under harsh conditions.

The nature and applications of optical materials have evolved rapidly in recent years. Their role as passive optical elements has been augmented by so-called photonic systems. These can have many active components-oscillators, amplifiers, frequency converters, modulators, switches, routers and so on, most of which rely, to some degree, on optical field confinement. The design of appropriate materials for this new technology involves progress on two separate levels. There is a need both for the optimization of microscopic electronic properties and for the separate control of bulk optical parameters on the scale of optical wavelengths.

Lanthanides ( $\mathrm{Ln}$ ) included in crystalline solids are used extensively in luminescent materials which employ practically any kind of energy as the excitation source. In order to avoid any decrease in luminescence efficiency, a very good homogeneity of the crystal lattice is required, and therefore, high temperatures are necessary to synthesize homogeneous Ln-doped crystals. In this sense, sol-gel technology offers an alternative way to prepare homogeneous and highly transparent materials at low temperatures, besides other facilities such as easy shaping, miniaturization, high purity of the precursors, possibility to combine organic and inorganic components providing the tunability of properties, etc. Nevertheless, sol-gel glasses can also present undesirable lattice defects. One of the consequences of these lattice defects can be a long afterglow, which is usually considered disadvantageous for practical applications, ${ }^{1}$ and may lead to the eventual rejection of the material.

On the other hand, the oscillator strength of lanthanides is very low in general, as a result of the fact that the transitions are forbidden by the La Porte rule. Intensity of luminescence can be then strongly increased by incorporating the lanthanide ions into a complex. Such complexes could be seen as light conversion molecular devices (LCMDs), coining the term "antenna effect" to donate the absorption, energy transfer, emission sequence involving distinct absorbing (the ligand) and emitting (the lanthanide ion) components, thus overcoming the very small absorption coefficients of the lanthanide ions. In these lanthanide-based emitting materials, luminescence properties depend on the efficiency of energy transfer from the absorption center (ligand) to the emission center (central ion) and on the concentration of quenchers $(\mathrm{OH}$ oscillators) surrounding the central ion. The studies of the decay times and the respective rate constants of these processes can lead to finding new materials with highly efficient emission at room temperature. ${ }^{2}$

The design of efficient lanthanide complexes, as molecular devices, became an important research goal in the 1990s. Interest in their photophysical properties has grown considerably since $\mathrm{Lehn}^{3}$ proposed the chelation of lanthanide ions with many different classes of ligands (e.g. cryptands, podands, calixarenes, macrocyclic ligands, $\beta$-diketones, heterobiaryl ligands, carboxylic acid derivatives, terphenyl ligands, proteins, etc.). ${ }^{4-6}$

Most of the complexes investigated emit red or green light $\left(\mathrm{Eu}^{3+}\right.$ and $\mathrm{Tb}^{3+}$ luminescence, respectively), but there are also complexes of different $\mathrm{Ln}^{3+}$ ions with luminescence in other spectral regions: near-IR $\left(\mathrm{Yb}^{3+}, \mathrm{Nd}^{3+}, \mathrm{Er}^{3+}\right)$, orange $\left(\mathrm{Sm}^{3+}\right)$, yellow $\left(\mathrm{Dy}^{3+}\right)$, blue $\left(\mathrm{Tm}^{3+}\right)$, or near-UV $\left(\mathrm{Ce}^{3+}, \mathrm{Gd}^{3+}\right)$. Unlike lanthanide ions in oxidic glasses, efficient LCMDs may find applications as luminescent probes in bio-medical assays and time-resolved microscopy, fluorescent lighting and luminescent sensors for chemical species $\left(\mathrm{H}^{+}, \mathrm{O}_{2}\right.$, halide ions, $\left.\mathrm{OH}^{-}\right)$, electroluminescent devices, UV dosimeters, or antireflection coatings for solar cells. Besides the quantum yield of a LCMD, other aspects, such as light output, solubility, volatility, and photothermal and thermodynamic stabilities may be critical to many applications.

These problems could be solved by incorporating lanthanide chelates in inorganic-organic hybrid materials, because they can offer multifunctionality and properties tailored from nanometric to millimetric length scales including mesoscopic and submicromic levels. That is why these materials could play a significant role in the field of micro- and nanophotonic devices (waveguides, emitting devices, quantum dot devices, photonic band gaps and holographic materials). The organic groups can modify the inorganic backbone by reducing the connectivity of the network allowing thick film deposition and lessening the processing temperature, very important for miniaturization devices and for reducing the processing cost. The composition and the process conditions can also be optimized to allow better control of the optical parameters (losses, refractive index, transmission), to reduce the processing temperature and to improve photosensitivity.

Organosilica-based inorganic-organic hybrids, synthesized through sol-gel processes, have been successfully employed for many purposes, such as sequestrating emitting species. It has been widely demonstrated that sol-gel process could be used to produce silica glasses with trapped Eu(III) fluorescent compounds. Organosilica hybrids have, as an advantage, very low solubility in water and many polar and non-polar solvents, as well as high thermal stability. ${ }^{7-9}$

During the past twenty years, optical studies performed on organic-inorganic nanocomposites have evolved towards different objectives: investigating the fundamental spectroscopy of lanthanide ions in the sol-gel environment, study of energy transfer between lanthanide ions and chelates (or dyes) in solid matrices, using luminescent molecules as probes for sol-gel processing, and finally developing materials with specific optical properties based on the properties of organic 
or inorganic chromophores. ${ }^{10-17}$ But in the past years, research of these luminescent materials has also been focused on bioanalytical and bio-medical applications.

In this review, the different synthetic strategies to prepare lanthanide-doped hybrid materials, as well as some basic considerations involving the efficiency and sensitization of lanthanide luminescence, are discussed. After that, a review of some of the most interesting devices and recent developments on luminescent Ln-doped hybrids used for advanced photonics and bio-medical areas will be commented.

\section{Chemical strategies for the design of luminescent lanthanide hybrid materials}

The advantages of sol-gel chemistry, such as low temperature processing and shaping, higher sample homogeneity and purity, the easy tailoring of composition and properties (mechanical, hydrophobicity, etc.), and the possibility to incorporate specific functions for particular purposes (organic functions, complexes, etc.), provide to the chemists the most useful tool for preparing very different types and families of multifunctional hybrid materials incorporating lanthanides.

A key point for the design of new luminescent hybrids is the tuning of the nature, extent, and accessibility of the inner interfaces. As a consequence, the nature of the organic and inorganic interface has been used to categorize hybrid materials into two main groups: Class I and Class II hybrids. ${ }^{18}$ Class I refers to hybrid compounds in which only hydrogen bonds or van der Waals forces exist between organic and inorganic constituents. In Class II hybrid materials, organic functionalities are covalently attached to the host matrix.

The main chemical routes to designing hybrid materials suitable for optical applications are schematized in Fig. 1. Path A corresponds to conventional sol-gel chemistry, where hybrid networks are obtained through the hydrolysis of metallic alkoxides condensed with or without organically modified metal alkoxides and incorporating lanthanide ions as salts or alkoxides. This strategy is simple and low-cost, and it yields amorphous hybrid materials where lanthanide ions are distributed within the host material according to the chemical nature affinity. These materials, that exhibit an infinite number of microstructures, can be transparent and easily shaped as films or monoliths, which is important for some advanced technologies, however, they are generally polydisperse in size and locally heterogeneous in chemical composition.

A better control of the local structures of these hybrid materials and their degrees of organization are important issues, especially if tailored optical properties are sought. Organization usually involves controlled segregation at the nanoscopic level. The main approaches to achieve organizedstructures, as schematized in Fig. 1, are routes B and C, which respectively provide organo- or bio-functional $\mathrm{Ln}$-doped nanoparticles and Ln-doped nanostructures with periodic porosity.

The synthesis of discrete luminescent nanoparticles (path B) has especially been explored in the past years because of their interesting properties (optical, magnetic, etc.) resulting under quantum confinement effects. Furthermore, the generation of these nanoparticles with novel properties opened a land of opportunities through functionalization with organic or even biocompatible groups. ${ }^{19-22}$

More recently, the organization and texturing of hybrid networks templated by organic structure-directing agents through self-assembly approaches ${ }^{23}$ (Fig. 1, route C) has provided new materials with potential uses in optics. The success of this strategy is clearly related to the ability that materials scientists have to control and tune hybrid interfaces. In this field, hybrid organic-inorganic phases are very interesting because of the versatility they demonstrate in building a continuous range of nanocomposites. Furthermore, the surface properties of these mesoporous or nanostructured

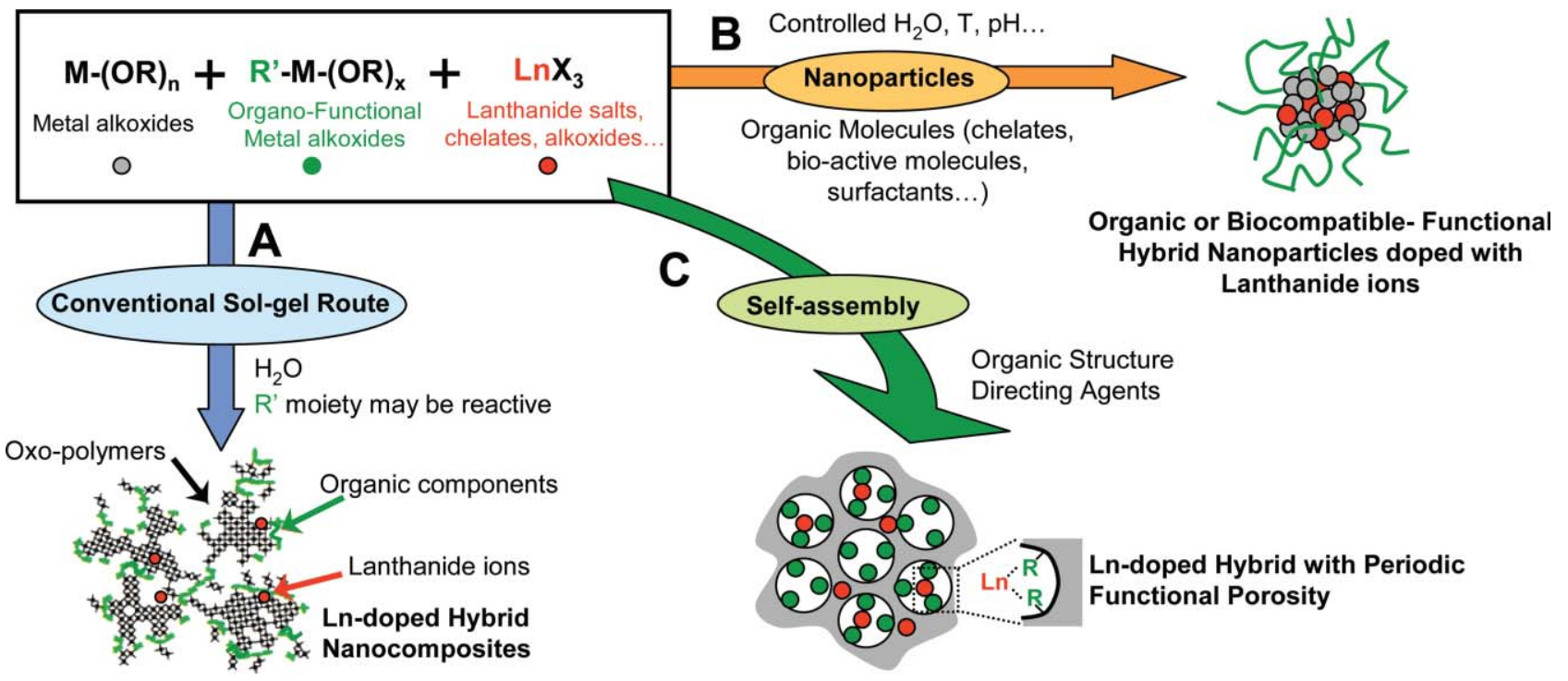

Fig. 1 Different pathways to prepare hybrid materials suitable for optical applications: the conventional sol-gel route (Path A) leads to traditional Ln-doped hybrids, Path B leads to Ln-containing nanoparticles (functionalized with organic or biomolecules) and Path C involves the use of templates capable of self-assembly, giving rise to meso-organized phases where lanthanide ions can be inside the walls or in the pores (figure adapted from ref. 35b). 
materials can be modified during the synthesis, by a "one-pot" method (incorporating organo-functionalized alkoxide precursors in the synthesis), or in a post-synthesis step (through reaction of $\mathrm{OH}$ surface groups with organic grafting agents). ${ }^{24-26}$ In this approach (route C) lanthanide ions can be directly included during the synthesis of the material and will be dispersed within the host matrix, or incorporated by impregnation after the synthesis, where lanthanide ions will interact with groups located at the surface (in general, specific grafting or chelating agents). Thus, modification of functional groups surrounding lanthanide ions provides modulation of their optical properties in terms of emission efficiency and wavelength and lifetimes, as will be further discussed.

\section{Efficiency and sensitization of lanthanide luminescence in Ln-doped hybrid materials}

Different important aspects must be taken into account in order to design a lanthanide-doped organic-inorganic hybrid material for optical purposes.

Most of the lanthanide cations present luminescent properties but the elaborate procedure using organic-inorganic hybrids severely limits the choice of the lanthanide cations. Roughly, the emission intensity is proportional to the energy gap between the emitting level and the level lying just below the emitting one. ${ }^{27}$ When the gap is small, the energy gap could be efficiently bridged by non radiative processes involving the vibrational states of organic compounds. According to these considerations, it first appears that the more interesting lanthanide cations are $\mathrm{Eu}^{3+}, \mathrm{Gd}^{3+}$ and $\mathrm{Tb}^{3+}$ which have some energy differences around $12000 \mathrm{~cm}^{-1}, 33000 \mathrm{~cm}^{-1}$ and $15000 \mathrm{~cm}^{-1}$ respectively. However, as $\mathrm{Gd}^{3+}$ absorbs and emits in the UV (at about $315 \mathrm{~nm}$ ), its optical features correspond to the organic part of the hybrid and this cation is not particularly studied. In the lanthanide series, other cations such as $\mathrm{Yb}^{3+}$ (energy gap of $10500 \mathrm{~cm}^{-1}$ ), $\mathrm{Sm}^{3+}$ and $\mathrm{Dy}^{3+}$ (energy gap of around $7500 \mathrm{~cm}^{-1}$ ) and even $\mathrm{Er}^{3+}$ and $\mathrm{Nd}^{3+}$ (energy gap of $5500 \mathrm{~cm}^{-1}$ ) are much more sensitive to local surroundings but have been recently extensively investigated even in cases where the quantum yield is in general quite low and improvements in the luminescence yields are observed after thermal treatment.

$\mathrm{Ln}^{3+}$ ions with the $[\mathrm{Xe}] 4 \mathrm{f}^{n}$ electronic configuration, have their $4 \mathrm{f}$ electrons shielded from the external interactions by filled $5 s^{2} 5 p^{6}$ levels and consequently the $4 \mathrm{f}-4 \mathrm{f}$ transitions are narrow, with small intensity. As a result of the low transition probabilities, emissions result in long-lived narrow emission bands. Consequently, direct excitation of the lanthanide ions is unfavorable and this problem can be solved by coupling species that are able to participate in energy transfer processes. This effect is called sensitization or the "antenna effect". In that case the excitation occurs in 3 steps: light is first absorbed by the immediate surrounding of the lanthanide. Energy is then transferred to the Ln cation (through the ligand triplet state for instance) and then the Ln ion emits light.

Investigating the energy transfer in more detail reveals that several situations could occur which correspond to a large variation in the $\mathrm{Ln}$ emission. A simplified scheme of the potential situation for the $\mathrm{Ln}$ and $\mathrm{S}$ state (Sensitizer) are

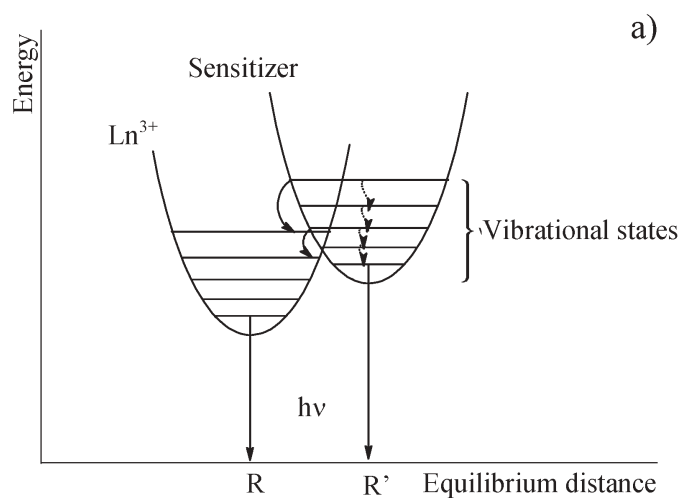

a)

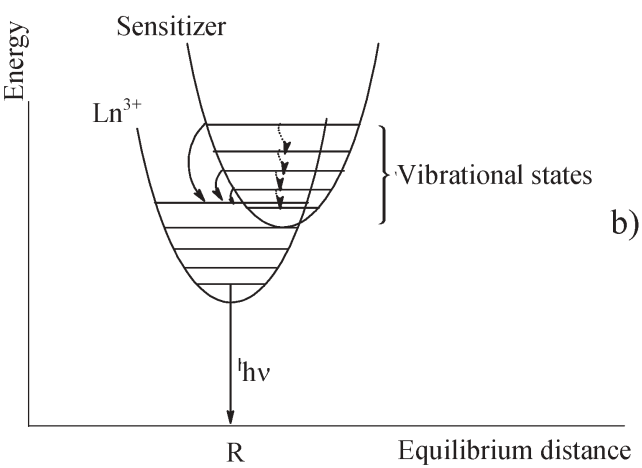

Fig. 2 A simplified scheme of the potential situation of the Ln and S state are presented in the coordinate configuration.

presented in the coordinate configuration in Fig. 2. For a relatively large variation in the equilibrium distance (Fig. 2a) the excitation in the vibrational levels of the sensitizer state leads to partial energy transfer to the Ln cation from the highest vibrational states. This energy transfer only occurs as long as these higher vibrational $\mathrm{S}$ states are populated, this means a short time and in that case $\mathrm{S}$ emission could be important. This case is indeed not very favorable to the Ln emission. On the other hand, if the equilibrium distances are closed as presented in Fig. 2b, the energy transfer is more favorable and transfer occurs as long as the $\mathrm{S}$ state is populated and energy could be more efficiently transferred to $\mathrm{Ln}^{3+}$ cation.

In addition to the radiative relaxation, nonradiative relaxation may occur by interaction of the electronic levels of the lanthanide ion with suitable vibrational modes of the environment. ${ }^{11}$ Transitions within a ligand field are related to acoustic phonons and are fast and very likely to occur. The efficiency of these processes depends on the energy gap between the ground and excited states as previously presented, as well as the vibrational energy of the oscillators. For example, when solvents containing $\mathrm{OH}$ groups are coordinated to lanthanide ions, efficient non-radiative deexcitation takes place through vibronic coupling with the vibrational states of the oscillators. Replacement of the $\mathrm{OH}$ oscillators (with typical energy of $3600 \mathrm{~cm}^{-1}$ ) by low-frequency OD oscillators (energy of $2200 \mathrm{~cm}^{-1}$ ), diminishes the vibronic deexcitation pathway. ${ }^{12}$ As an example, in the case of $\mathrm{Tb}^{3+}$ with a large energy gap of $14800 \mathrm{~cm}^{-1}$, the number of phonons required to fill this gap is 7 phonons for OD vibrations while it is only 4 for the $\mathrm{OH}$ 
groups. Therefore, with OD groups, the $\mathrm{Tb}^{3+}$ lifetime from the ${ }^{5} \mathrm{D}_{4}$ emitting level is $3.8 \mathrm{~ms}$ at $300 \mathrm{~K}$ while it is only $0.47 \mathrm{~ms}$ in aqueous solution.

Other oscillators such as $\mathrm{NH}$ and $\mathrm{CH}$ with energy respectively about $3300 \mathrm{~cm}^{-1}$ and $2900 \mathrm{~cm}^{-1}$ should be taken into account when such groups are located in the first coordination sphere of the Ln cation. It should be noticed that as multipolar-multipolar interactions are usually responsible for such a quenching mechanism, with a predominant effect on the dipole-dipole interaction, the energy transfer rate between the excited metal ion state and the vibrating oscillator vary as $k_{\mathrm{NR}}=\mathrm{Kr}^{-6}, r$ being the distance between the Ln cation and the vibrating oscillator.

Maas et al. ${ }^{13}$ in a paper dedicated to Prof. R. Hoffmann on the occasion of his 65th birthday have for instance reported three ways to overcome the difficulties of low absorption and thermal relaxation: (i) matrix excitation followed by energy transfer to the lanthanide ion, (ii) ligand to metal charge transfer followed by lanthanide $\mathrm{f}-\mathrm{f}$ emission, and (iii) ligandcentered absorption followed by energy transfer to the lanthanide ion.

However, conventional ligands do not usually give rise to inert complexes because the lanthanide ions are unable to form strong coordination complexes as a result of their electronic configuration. Depending on the solvent, this situation leads to a competition for the coordination sites between ligands and solvent molecules.

Modeling the mechanisms of energy transfer between lanthanide ions was extensively described in the seventies but in 1997, Malta ${ }^{28}$ proposed a theoretical approach to similarly describe the energy transfer processes occurring between ligands and lanthanides in luminescent complexes. Energy transfer rates have therefore been determined ${ }^{4,29}$ in different cases.

Then, a theoretical approach for the intramolecular energy transfer process involving the ligand to metal charge transfer (LMCT) state in Ln compounds was very recently proposed. ${ }^{30}$ Expression of the selection rules is derived and energy transfer rates calculated. It appears that the channel LMCT (see Fig. 3) could be several orders of magnitude more important than other channels. ${ }^{30}$ Of course the emission intensity strongly depends on the relative energy level position of the ligand to metal charge transfer (LMCT) state in comparison to the $\mathrm{Ln}^{3+}$ excited state levels as presented Fig. 3 and according to the relative position, the transfer rate and back transfer rate can be estimated. Therefore, the energy levels position could be tuned as presented in Fig. 3 from ref. $31 a$.

For A-type calixarenes ligands, ${ }^{31}$ the energy level position lies above the ${ }^{5} \mathrm{D}_{J}$ levels $\left(J=0\right.$ and $J=4$ for $\mathrm{Eu}^{3+}$ and $\mathrm{Tb}^{3+}$, respectively) and its energy could be transferred with phonon assistance to $\mathrm{Eu}^{3+}$ and $\mathrm{Tb}^{3+}$ ions. However, at this high energy level position $\mathrm{O} \rightarrow \mathrm{Eu}^{3+}$ ligand to metal charge transfer (LMCT) could occur and lead to non radiative deexcitation. ${ }^{32}$ This prevents the energy transfer through $\mathrm{Eu}^{3+}$ cations, but not to $\mathrm{Tb}^{3+}$. Indeed $\mathrm{O}-\mathrm{Tb}^{3+}$ charge transfer band is lying about $3 \mathrm{eV}$ above the $\mathrm{O} \rightarrow \mathrm{Eu}^{3+}$ charge transfer band. ${ }^{33}$ The measured efficiency of the emission could be estimated from the quantum yield reported to be $0.2 \%$ for $\mathrm{Eu}^{3+}$ and $16 \%$ for $\mathrm{Tb}^{3+}$.
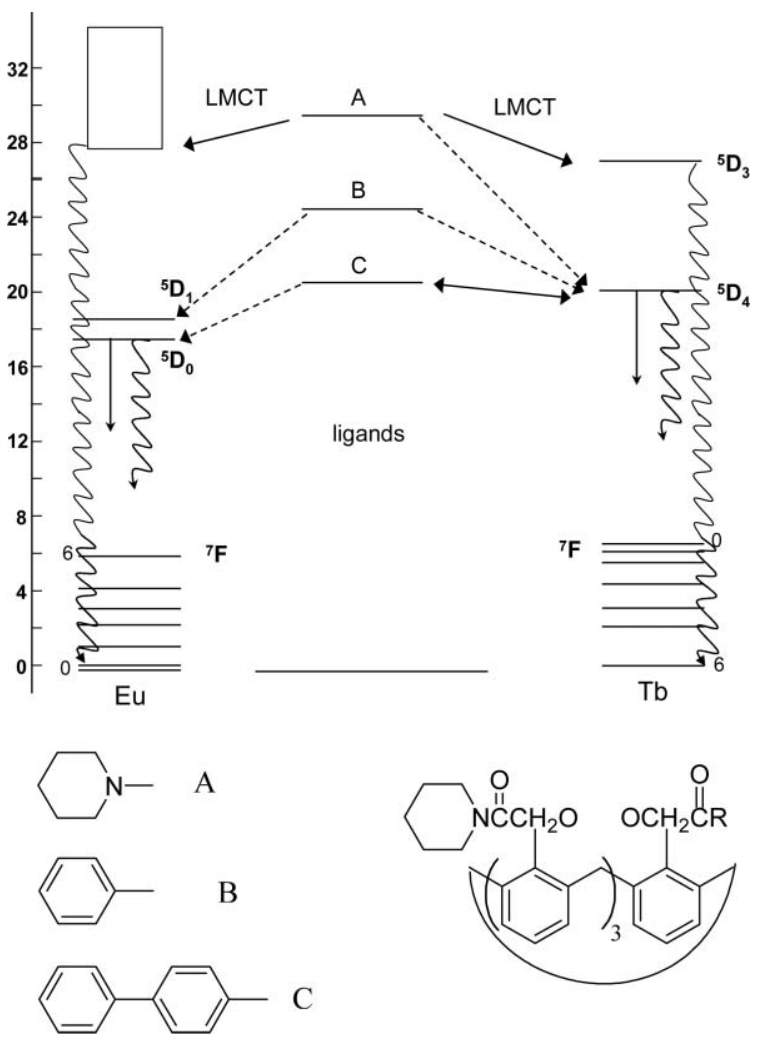

Fig. 3 A simplified scheme of the sensitization of $\mathrm{Eu}^{3+}$ ions by the antenna effect, in which the energy level positions of the ligand can be tuned with $R=\mathrm{A}, \mathrm{B}$ or $\mathrm{C}$ (redrawn from ref. 31).

When a phenyl group is added instead of a non-conjugated organic moiety giving ligand B (Fig. 3), the lowest triplet excited state is shifted to lower energy and both $\mathrm{Eu}^{3+}$ and $\mathrm{Tb}^{3+}$ could be sensitized. In addition, as phenyl groups provided a better resonance, the quantum yield values are $6 \%$ and $27 \%$ for the $\mathrm{Eu}^{3+}$ the $\mathrm{Tb}^{3+}$, respectively.

Finally, replacing the phenyl group by a biphenyl unit to give ligand C (Fig. 3) will further lower the energy level, yielding good resonance with the $\mathrm{Tb}^{3+}$ energy level. In that case, efficient transfer but also efficient back transfer occur and the luminescence of the $\mathrm{Tb}^{3+}$ ion is no more sensitized as the quantum yield is $0.01 \%$, while the quantum yield of the $\mathrm{Eu}^{3+}$ is kept at $6.1 \%$.

Careful measurements of the quantum yields and effort on understanding the numerous energy transfers processes (between lanthanides, between ligands and lanthanides or for instance between ligand-to-Ln charge transfer states) are very important in order to well understand the properties of luminescent lanthanide-doped organic-inorganic hybrids. ${ }^{34}$

\section{Devices and developments of lanthanide-doped hybrid materials}

\subsection{Luminescence of lanthanide ions in amorphous hybrid materials (route A)}

Lanthanide-doped hybrid materials prepared by conventional sol-gel routes (path A in Fig. 1) have extensively been studied $^{35-41}$ since they present special interest for solid-state 
lasers and fiber amplifiers, as alternative materials to traditional organic dyes.

Laser dyes have been used for many years as a versatile source of a tunable coherent optical radiation, and are still commonly used both in lasers and in optically pumped amplifiers.

Tunable solid-state organic lasers with dye-doped polymer gain media have been demonstrated to yield narrow-linewidth, ${ }^{14,15}$ single-longitudinal-mode (SLM) ${ }^{16,17}$ emissions in compact multiple-prism grating oscillator configurations. The excellent optical homogeneity of these materials is one of the most important features. Nevertheless, polymer gain media exhibit limitations on the pulse repetition frequency ${ }^{42}$ and, ultimately, on the average power of these lasers. Moreover, most of the dye lasers are solvent-based and require pumping of the dye solution through a resonator to slow down photodecomposition. Therefore, encapsulation of the dye in a solid matrix is favorable to provide ease of use and replacement, and also for decreasing health and environmental hazards. Costela et al. have published an interesting review of dye-doped polymer laser gain media ${ }^{43}$ and photophysical characteristics have been investigated by Holzer et al. ${ }^{44}$

Most of the recent dye-doped emitting materials for tunable solid-state lasers are Class II organic-inorganic hybrids prepared by conventional sol-gel techniques in which luminescent lanthanide organic complexes are anchored to a siloxane matrix via $\mathrm{Si}-\mathrm{C}$ linkages. ${ }^{45,46}$ The strategy to prepare such materials is to design new organoalkoxysilanes, which combine a chromophore unit that can efficiently absorb the incident light, chelating functions that can bind to the $\mathrm{Ln}^{3+}$ ions and trialkoxysilyl groups that act as the inorganic network precursors.

For some applications, the presence of dyes is not required or even undesirable, and lanthanides are introduced as free ions. A complete review ${ }^{47}$ reports a list of sol-gel derived hybrid materials with emission properties and improved thermal properties. Here, one-pot synthesis of different trivalent lanthanide $\left(\mathrm{Eu}^{3+}, \mathrm{Nd}^{3+}, \mathrm{Sm}^{3+}, \mathrm{Dy}^{3+}, \mathrm{Er}^{3+}\right.$ and $\mathrm{Tm}^{3+}$ )-doped hybrid siloxane-oxide materials are included. In these nanocomposites, the dispersion of the $\mathrm{Ln}^{3+}$ ions mainly depends on the extent and nature of the oxidic part. ${ }^{48}$

The stabilization of lanthanide ions in their low oxidation states, such as $\mathrm{Ce}(\mathrm{III})$ (Fig. 4) and $\mathrm{Eu}(\mathrm{II})$, inside amorphous hybrid materials is also possible thanks to in situ generation of reducing species $\left(\mathrm{H}_{2}\right)$ from reaction with organo-hydrosilanes. ${ }^{49,50}$ In this case, the cleavage of the $\mathrm{Si}-\mathrm{H}$ bonds at room temperature is catalyzed by transition metal alkoxides.

However, in all these studies, the previously mentioned $\mathrm{OH}$ quenching phenomena are underlined because of the low temperature synthesis (typically $<150{ }^{\circ} \mathrm{C}$ ), and the radiative lifetime of emission and the resulting luminescence intensity are usually quite low. Despite this, optimization of the sol-gel synthesis conditions and mild thermal treatments provide, for instance, lifetimes of around $100 \mu$ s for $\mathrm{Nd}^{3+}$-doped hybrid materials, ${ }^{51}$ which is a reasonably good value when it is taken into account that neodymium is one of the most sensitive lanthanide to $\mathrm{OH}$ oscillators.

The choice of bulky aromatic ligands is therefore critical to decrease $\mathrm{OH}$ quenching as well as to isolate the emitting

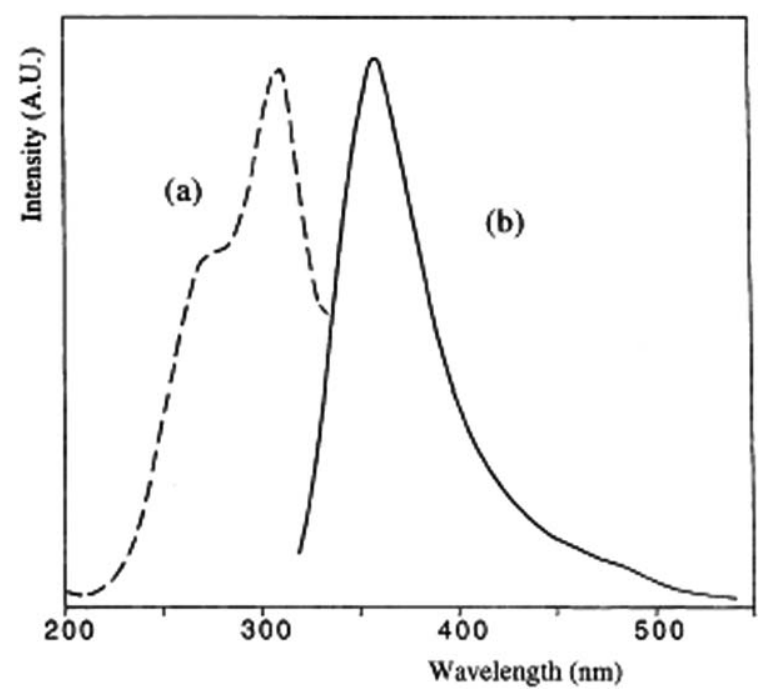

Fig. 4 Room temperature excitation (a) and emission (b) spectra of in situ generated $\mathrm{Ce}^{3+}$-doped hybrid material $\left(\lambda_{\text {exc }}: 300 \mathrm{~nm}\right.$ for the emission) prepared from reaction between a $\mathrm{Ce}^{4+}$ salt and $\mathrm{HSi}(\mathrm{OEt})_{3}$ in a mixture of other silanes.

centers. Covalent attachment between organic and inorganic components seems beneficial for achieving high luminescence yields for the following reasons: (i) leaching of the active molecules is avoided, (ii) higher concentrations of doping ions can be reached, (iii) clustering of the emitting species is prevented and (iv) materials with better homogeneity can be obtained. Some examples of how organic components, synthesis conditions and post-synthesis treatments are critical in the optical response of luminescent hybrids are detailed in the following paragraphs.

The study performed by Trejo-Valdez et al. ${ }^{52}$ is quite illustrative. They prepared ORMOSIL (organically modified silicates) films doped with $\mathrm{Tb}^{3+}$ and different aromatic ligands by aerosol-gel process. The effect of the baking temperature on the optical response was evident: the photoluminescence (PL) intensity at $545 \mathrm{~nm}$ increased with baking temperature (from 25 to $150{ }^{\circ} \mathrm{C}$ ), which is attributed to a partial elimination of quenching species (residual solvents, water and hydroxyl groups). When $\mathrm{Tb}^{3+}$ ions were incorporated without aromatic ligands, they should be stabilized through complexation with free methacrylic acid, being positive for the PL properties. On the other hand, complexation of $\mathrm{Tb}^{3+}$ ions with aromatic ligands improved the encapsulation and enhanced PL properties of the films, owing to an efficient intramolecular energy transfer (IMET) process. However, films doped with different complexes exhibit non-exponential PL decays, indicating that terbium ions are distributed in different spectroscopic environments. The results suggest therefore that PL properties are conjointly influenced by the ligand to $\mathrm{Tb}^{3+}$ ion energy transfer and by encapsulation effects, which strongly depend on the ligand nature.

Potential applications of this family of optically active ORMOSIL films doped with lanthanide complexes rely on the design of optical waveguides as well as integrated display or lighting devices, but further studies are still necessary to improve the active properties of these films for commercial applications. 
Another interesting family of optically active ORMOSILs are those prepared by Franville et al. ${ }^{46,53}$ They consist on lanthanide $\left(\mathrm{Eu}^{3+}, \mathrm{Gd}^{3+}\right)$ organic complexes covalently attached to the sol-gel silica-based network. Four dicarboxylic acids with different aromatic subunits (derivates of pyridine and picolinic acid) have been chosen as ligands for $\mathrm{Ln}^{3+}$ ions. In this case, the strategy of synthesis involved the grafting of these ligands to 3-aminopropyltriethoxysilane (APTES), providing organically modified alkoxysilanes that were used as molecular precursors for the preparation of hybrid materials.

It was shown that modification of the ligand structure (mono- or disubstituted amides) led to different coordinating properties and to variable absorption edges. As a result, the absorption efficiency as well as the ability of the chelates to transfer the absorbed energy to $\mathrm{Ln}^{3+}$, and consequently the quantum yield of the emission, changed.

Emission features upon direct excitation of the $\mathrm{Eu}^{3+}{ }^{5} \mathrm{D}_{0}$ energy level showed the presence of two different site distributions in the four hybrid compounds. Variations in the relative emission intensities were observed according to the nature of the organic chromophore. These variations were discussed in relation to the ATE (absorption-transfer-emission) mechanism and to the relative energy positions of the ligand and the lanthanide ions respectively. The main paths of energy transfer between the excited ligand and $\mathrm{Ln}^{3+}$ states are summarized in Fig. 5. By the other hand, the effect of the silica matrix was studied, showing an effect of broadening of the emission peaks, whereas spectral repartitions and lifetimes remained unchanged as compared with the corresponding organic molecules.

Other researchers such as Jenouvrier ${ }^{54}$ obtained other interesting optically active materials at low temperature by incorporation of titania in the inorganic matrix. Concretely, $\mathrm{Tb}^{3+}-\mathrm{SSA}$-doped $\mathrm{SiO}_{2}-\mathrm{TiO}_{2}$ thin films (SSA, sulfosalicylic acid) were deposited by an original aerosol-gel process at $40{ }^{\circ} \mathrm{C}$, and then heat-treated at $150{ }^{\circ} \mathrm{C}$. The complexation of $\mathrm{Tb}^{3+}$ ions by sulfosalicylic acid (SSA) improves their active properties, leading to a material of high optical quality suitable

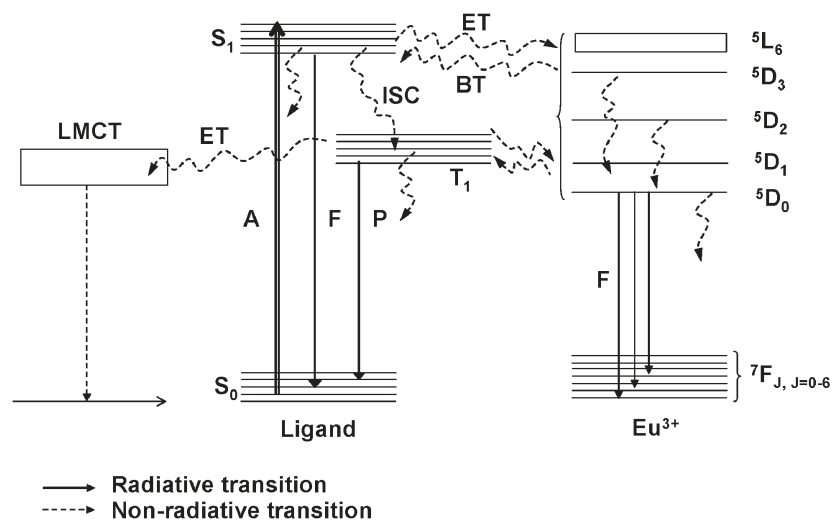

Fig. 5 Sensitization mechanism of $\mathrm{Eu}^{3+}$ luminescence in organic complexes within an ORMOSIL. On the left side, fluorescence quenching is observed when $\mathrm{T}_{1}$ transfers its energy to a LMCT state. The abbrevations are: $\mathrm{A}=$ absorption, $\mathrm{F}=$ fluorescence, $\mathrm{P}=$ phosphorescence, ISC = inter-system crossing, ET = energy transfer, $\mathrm{BT}=$ back energy transfer, $\mathrm{LMCT}=$ ligand-to-metal charge transfer. for planar waveguides. Moreover, this approach can be extended to other lanthanide elements, opening a wide range of integrated optics applications on thermally sensitive substrates. The introduction of several lanthanide elements emitting in the visible region would also permit the use of these films for color displays.

Usually, lanthanide nanoparticles in bulk monoliths aggregate easily, and much research has been done in order to solve this problem. In this sense, Ji et al. ${ }^{55}$ have prepared transparent and crack-free organic-inorganic hybrid monoliths containing lanthanide complexed nanoparticles $\left[\mathrm{Eu}(\mathrm{TTA})_{3}\right.$ Phen, where TTA: trifluorothenoyl-acetone, Phen: 1,10-phenanthroline], by using tetraethyl orthosilicate and a monomer, hydroethylmethacrylate (HEMA). In these monoliths, the nanoparticles of complexed-lanthanide are dispersed into organic-inorganic semi-interpenetrating networks and the resulting nanostructured hybrids exhibit high luminescence intensity and high color purity with a half-width of less than $15 \mathrm{~nm}$. Moreover, the fluorescence lifetimes are longer than the original lanthanide complexes. In this case, the interpenetrating network does not destroy the energy transfer from ligands to lanthanide ions.

Another great family of Ln-nanohybrids is the one classified as di-ureasils. Sá Ferreira et $a l^{56}$ have extensively reported the energy transfer mechanisms and emission quantum yield measurements of sol-gel $\mathrm{Eu}^{3+}$-doped di-ureasils. Termed as $\mathrm{U}(2000)$ and $\mathrm{U}(600)$, they include urea cross-linkings between a silicate backbone and polyether-derived segments of two molecular weights, 2000 and 600, respectively (see Fig. 6a). These materials are full-color emitters in which the $\mathrm{Eu}^{3+}$ ${ }^{5} \mathrm{D}_{0} \rightarrow{ }^{7} \mathrm{~F}_{0-4}$ red lines merge with the broad green-blue emission of the nanoscopic matrix's backbone. The excitation spectra show the presence of a large broad band $(\sim 27000$ $29000 \mathrm{~cm}^{-1}$ ) assigned to a ligand to-metal charge transfer state. Emission quantum yields ranged from $2 \%$ to $13.0 \%$ depending on the polymer molecular weight and $\mathrm{Eu}^{3+}$ concentration. Energy transfer between the hybrid hosts and the cations arises from two different and independent processes: the charge transfer band and energy transfer from the hybrid's emitting centers. The activation of the latter mechanisms induces a decrease in the emission quantum yields (relative to undoped nanohybrids) and permits a fine-tuning of the emission chromaticity across the CIE (Commission Internationale d'Eclairage) diagram, e.g., $(x, y)$ color coordinates from $(0.21,0.24)$ to $(0.39,0.36)$. Moreover, that activation depends noticeably on the local coordination. For the di-ureasils with longer polymer chains, energy transfer occurs as the $\mathrm{Eu}^{3+}$ coordination involves the carbonyl-type oxygen atoms of the urea bridges, which are located near the hybrid's host emitting centers. On the contrary, in the U(600)based di-ureasils, the $\mathrm{Eu}^{3+}$ ions are coordinated to the polymer chains, and therefore, the distance between the hybrid's emitting centers and the metal ions is large enough to allow efficient energy transfer mechanisms.

The di-urea or di-urethane cross-linked poly(ethylene oxide) (PEO)-siloxane structures (named di-ureasils or urethanesils, respectively) are promising hybrids for the fabrication of large area neutron detectors, ${ }^{57}$ as nanocomposite gel electrolytes for dye-sensitized photoeletrochemical cells and as efficient 
a)

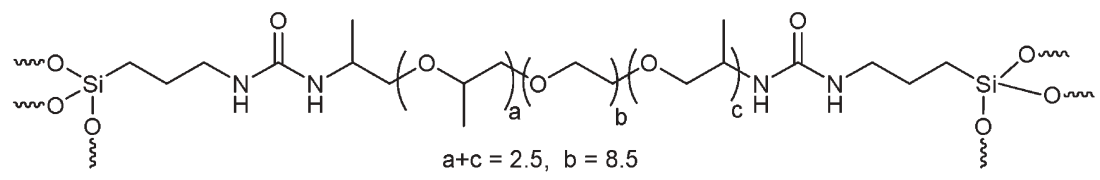

b)<smiles></smiles>

c)

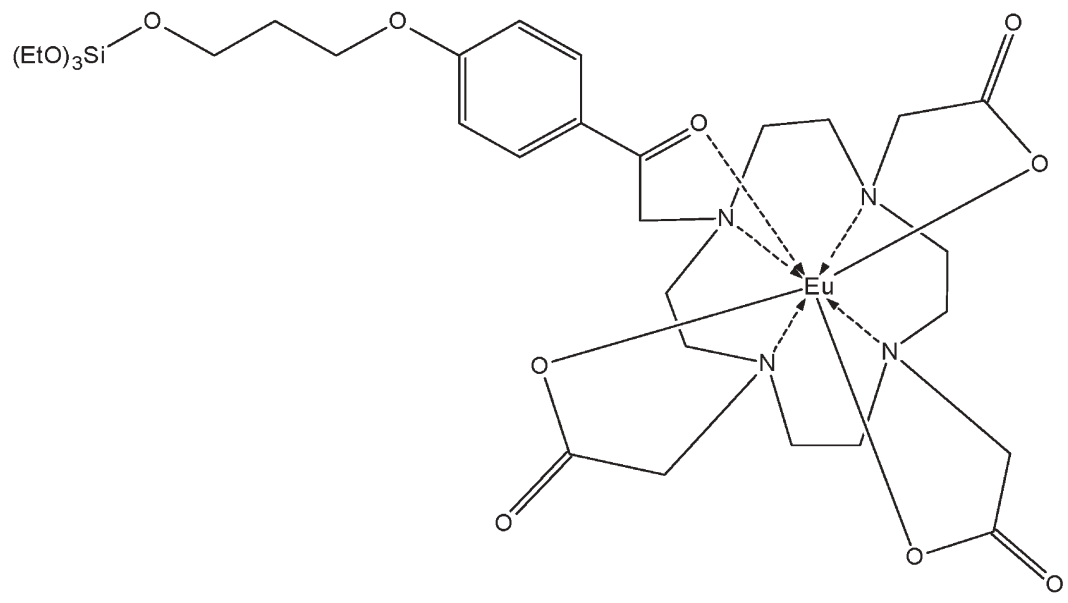

Fig. 6 (a) Chemical structure of U(600) di-ureasil hybrid, (b) Eu(nta) $)_{3} \cdot$ bpy complex and (c) chemical structure of the Ln-complex linked to the silica matrix.

white-light room temperature emitters (quantum yield of 10-20\%). ${ }^{58-65}$ These materials can be prepared through hydrolysis and condensation of the corresponding organicinorganic hybrid precursors obtained from the reaction of the terminal amine groups of PEO-containing diamines [or the hydroxyl groups of poly(ethylene glycol) for di-urethanesils] with the isocyanate group of 3-isocyanatopropyltriethoxysilane (ICPTES). ${ }^{56}$ Alternatively, di-ureasils and di-urethanesils can be produced via acetic acid (AA) or valeric acid solvolysis ${ }^{57,58}$ displaying an emission quantum yield $27-35 \%$ higher than that calculated for the analogues synthesized via conventional sol-gel techniques. ${ }^{58}$ Furthermore, transparent and optically uniform di-ureasil films doped with a $\mathrm{Eu}^{3+}$ complex with thenoyltrifluoroacetone and 2,2'-bipyridine (bpy) ligands were prepared by AA solvolysis. ${ }^{62} \mathrm{The}^{\mathrm{Eu}^{3+}}$ emission, whose maximum intensity value is approximately
$60 \%$ of that of Rhodamine-B, results from excitation of the ligand levels and subsequent intramolecular energy transfer to the $4 \mathrm{f}$ states. Although the organic-inorganic matrix also seems to contribute to these energy transfer processes, the nature of this contribution was unclear. ${ }^{62}$

The white-light photoluminescence (PL) of di-ureasils results from a convolution of donor-acceptor pair recombinations that occur in the $\mathrm{NH}$ groups of the urea linkages and in $\mathrm{O}-\mathrm{O}-\mathrm{Si} \equiv\left(\mathrm{CO}_{2}\right)$ oxygen-related defects of the siliceous nanodomains. ${ }^{59-61,66}$ Energy transfer between these hybrids' emitting centers and the $\mathrm{Eu}^{3+}$ ions has been quantitatively discussed elsewhere. ${ }^{54,63,65}$ The activation of these energy transfer mechanisms noticeably depends on the $\mathrm{Eu}^{3+}$ local coordination to the carbonyl group of the urea cross-linkages. Moreover, that activation induces a decrease in the emission quantum yield (relative to that of the undoped nanohybrids) 
and permits a fine-tuning of the emission chromaticity across the CIE diagram. ${ }^{54,63,67}$

$\mathrm{Fu}$ et $a l^{68}$ have prepared di-ureasil organic-inorganic hybrids incorporating Eu(nta) $)_{3}$.bpy [where nta and bpy stand for 1-(2-naphthyl)-4,4,4-trifluoro-1,3-butanedionate and 2,2'bipyridine, respectively] by AA solvolysis and the conventional hydrolysis-polycondensation sol-gel route (see Fig. 6b). An effective interaction between the $\mathrm{Eu}(\mathrm{nta})_{3} \cdot$ bpy complex and the carbonyl groups of the urea linkages was demonstrated. Moreover the dimension and the degree of condensation of the siloxane nanodomains noticeably depends on the synthesis route. The PL spectra of these Eu(III)-based di-ureasils displays essentially the typical ${ }^{5} \mathrm{D}_{0} \rightarrow{ }^{7} \mathrm{~F}_{0-4}$ intra- $4 \mathrm{f}^{6} \mathrm{Eu}^{3+}$ transitions. Indeed the broad emission band typical of aminefunctionalized hybrid hosts was not detected suggesting, therefore, the activation of energy transfer channels between the hybrid host's emitting centers and the Eu(III) ions. The efficiency of these energy transfer channels depends on the synthesis strategy adopted as the overall emission quantum yield and the ${ }^{5} \mathrm{D}_{0}$ quantum efficiency strongly decreases for the di-ureasil prepared through solvolysis, relative to that synthesized by conventional hydrolysis (from 15 to $6 \%$ and from 60 to $46 \%$, respectively). Furthermore, as the $\mathrm{Eu}^{3+}$ first coordination shell is essentially independent of the synthesis method, the changes detected on the hybrid host-to-ligands-to-Eu ${ }^{3+}$ ion energy transfer channels should be primarily induced by the interaction between the hybrid emitting centers ( $\mathrm{NH}$ groups of the urea linkages and oxygen-related defects of the siliceous nanodomains) and the nta and bpy ligands, favoring, therefore, a larger non-radiative transition probability in the diureasils prepared through AA solvolysis. Thus, the tuning of the efficiency of the hybrid host-to-ligands-to- $\mathrm{Eu}^{3+}$ ion energy transfer channels with the subsequent changes in the overall emission quantum yields might be achieved by promoting differences in the dimensionality and structure of the siloxane domains through the embracing of different synthesis strategies. A suitable choice of ligands that better sensitize the $\mathrm{Eu}^{3+}$ emission, together with a fine control of the synthesis process attending to the optimization of the radiative hybrid host-to$\mathrm{Eu}^{3+}$ energy transfer efficiency, definitely endorses the design of nanohybrids with better emission conversion performances and higher absolute quantum yields.

One of the most important problems often encountered upon embedding the luminescent complexes in the host matrix is the inhomogeneous distribution of the compounds, ${ }^{69,70}$ which leads to clustering of lanthanide ions and hence a decrease of the luminescence intensity. ${ }^{71,72}$ To solve this problem, Lenaerts et al., ${ }^{73}$ have proved that a 2 -substituted imidazo[4,5-f]-1,10-phenanthroline is an easily accessible, stable, and versatile building block for covalent attachment of lanthanide $\beta$-diketonate complexes to a hybrid matrix. Bulk samples and thin films were prepared with Ln(III) 2-thenoyltrifluoroacetonate complexes $(\mathrm{Ln}=\mathrm{Pr}, \mathrm{Nd}, \mathrm{Sm}, \mathrm{Eu}, \mathrm{Dy}, \mathrm{Ho}$, $\mathrm{Er}, \mathrm{Tm}, \mathrm{Yb}$ ) grafted via the imidazo-[4,5-f]-1,10-phenanthroline moiety to the silica hybrid matrix. They are versatile because 4-hydroxybenzaldehyde, which is used to prepare the substituted imidazole ring, can be replaced by other functionalized aldehydes. Additionally, the imidazole ring can be alkylated or even quaternized.
The presence of the function imidazol in this grafting molecule is quite important, since in previous works, these authors used 5-amino-1,10-phenanthroline as a starting compound $^{74-76}$ and, although the approach was successful, this molecule presented a low stability.

The luminescence performance of the lanthanide complexes in these thin films is very good, especially in the europium(III) complex which is highly luminescent. Of importance here is the observation of lanthanide-centered near-infrared luminescence in $\mathrm{Pr}(\mathrm{III}), \mathrm{Sm}(\mathrm{III})$, and Ho(III) complexes.

With these examples, we want to illustrate the versatility in terms of composition and luminescent response of Ln-hybrid nanocomposites. In general, many hybrid materials present the paramount advantage to both facilitate integration, miniaturization and multifunctionalization of devices, opening a land of opportunities for "nanophotonics".

In particular, the exploitation of coatings with optical properties is still strongly rising. Two recent examples of highly stable red and green-emitting sol-gel transparent coatings have been developed for example by the groups of Armelao ${ }^{77}$ and Franville (unpublished results). In both cases, they consist of highly luminescent films of Class II organic-inorganic hybrids activated by $\mathrm{Tb}^{3+}$ (green) and $\mathrm{Eu}^{3+}$ (red) under UV excitation. The structure of the trivalent lanthanide complex linked to a silica matrix developed by Armelao is depicted in Fig. 6c. Pictures of highly luminescent films developed by Franville et al. are shown in Fig. 7. Both systems can find real applications in tunable light emitting OLED devices. In conclusion, optically active hybrids containing lanthanide ions present a very attractive field to realise applications for this century.

\subsection{Luminescence of lanthanide ions as a probe in mesostructured materials}

Until now we have discussed the synthesis and potential applications of Ln-doped hybrids where lanthanide ions are homogeneously dispersed within the matrix. However, incorporation of photoactive molecules in specific regions of mesostructured silicate films is attracting increasing interest.

Several methods of preparing these structured films are being explored. One of the methods involves preparing the films and then backfilling the pores with the desired molecules. $^{78-85}$

When the molecules contain alkoxysilane groups, they can be used to functionalize the newly exposed pore surfaces. For instance, the entrapment of lanthanide complexes into

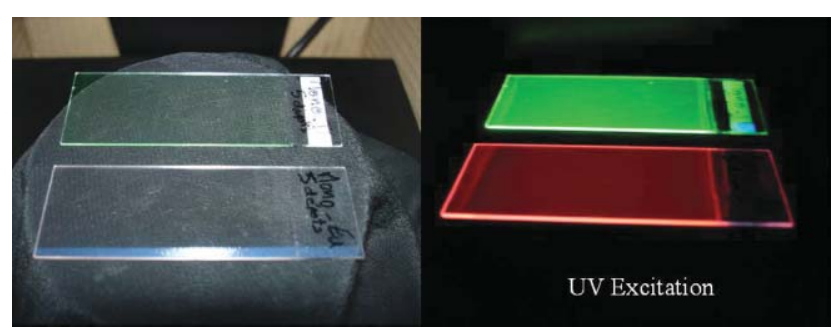

Fig. 7 Examples of transparent luminescent dip-coated films prepared using a sol-gel technique: organic-inorganic hybrids (Class II) activated by $\mathrm{Tb}^{3+}$ (green) and $\mathrm{Eu}^{3+}$ (red) (from A. C. Franville, N. GaillardCapera and R. Mahiou, unpublished results, with permission). 
surface-modified mesoporous silica (MCM41, MCM48 and SBA15) by a two-step procedure has been widely studied. ${ }^{86-92}$ In general, a lanthanide complex interacts with its surrounding silylating agents through weak hydrogen-bonding interactions, and optical processes (emission intensity, wavelength and lifetime) can be modulated depending on the lanthanide coordination.

An alternative method exploits a one-step method ("one-pot" synthesis) that opens the possibility of making new types of photoactive materials. ${ }^{25}$ In this approach, all components including the photoactive molecules and the structure-directing agents are dissolved in the starting sol. The dip coating ${ }^{93}$ of this sol onto a substrate produces, in a single step, doped mesostructured films. The advantages of using this methodology are the easier incorporation of the doping ions within the material than in a post-synthesis impregnation procedure. Furthermore, the one-pot method allows higher doping levels than are achievable by backfilling, and give access to regions other than empty pores.

The earliest works on one-pot preparations of films used luminescent molecules to probe the film formation. ${ }^{94,95}$ In these studies, a luminescent probe was used to monitor micelle formation and to correlate this process with changes in solvent composition during rapid film formation. Luminescent molecules that were preferentially located in specific parts of the structured material (micelles, matrix walls, surfaces, etc...) were used to know the properties of specific regions of the films. ${ }^{96,97}$

Efforts to modify the composition of the silica framework itself have also been reported. ${ }^{98}$ Typical studies use organically substituted alkoxysilane precursors such as $\mathrm{RSi}(\mathrm{OR})_{3}$, where $\mathrm{R}$ is an alkyl or aryl group. These groups are chosen because of their hydrophobic properties, not optical function. Recently, deliberate placement of luminescent molecules in three spatially separated regions of mesostructured films templated by ionic surfactants was reported. These regions were defined as the silicate matrix, the hydrophobic core of surfactant micelles, and the intervening ionic interface between surfactant head groups and the silica framework. Designed placement of two or more molecules is also feasible but has not yet been demonstrated.

Lanthanide ions have been used as probes in quantum $\operatorname{dots}^{99}$ and also can be incorporated in this type of mesostructured materials. Some reports have described mesoorganized hybrid systems in which lanthanide ions are complexed by chelating agents covalently linked to the silica framework. As already mentioned, encapsulation of lanthanide complexes in matrices is one of the strategies to prepare effective emitting Class II hybrid materials ${ }^{11 b, 100}$ and avoid the leaching of lanthanide ions.

In the course of studying nanostructured hybrid materials, matrices incorporing phosphines and phosphine derivatives bearing two or three hydrolyzable $\mathrm{Si}(\mathrm{OR})_{3}$ groups are of interest. ${ }^{101}$ It has been demonstrated the importance of the number of hydrolyzable $\mathrm{Si}(\mathrm{OR})_{3}$ groups for the accessibility of phosphorus centers incorporated within the corresponding materials. ${ }^{102}$ With a view to preparing hybrid materials with luminescence properties, it was taken into account the well-known binding affinity of phosphine oxides toward the lanthanide ions ${ }^{103,104}$ to prepare europium complexes with phosphine oxides bearing one, two, or three hydrolyzable $\mathrm{Si}(\mathrm{OR})_{3}$ groups as ligands. Indeed, among the lanthanide ions, europium is a particularly attractive luminescent center due to its long-lived and narrow-width emission band. ${ }^{105}$

Embert et al. ${ }^{106}$ have shown that hydrolysis and polycondensation of isolated $\mathrm{Eu}^{3+}$ complexes of phosphine oxides bearing one hydrolyzable $\mathrm{Si}(\mathrm{OR})_{3}$ group afforded nanostructured hybrid materials in which $\mathrm{Eu}^{3+}$ ions are well encapsulated. They have examined the influence of the number of $\mathrm{Si}(\mathrm{OR})_{3}$ groups on the degree of encapsulation of $\mathrm{Eu}^{3+}$. The synthetic approach gave nanostructured hybrid materials with improved luminescence properties since the local environment around the emitting species is unique. Indeed, as the complexation survives the sol-gel process, clustering of the emitting species was thus prevented. It was shown that there were no $\mathrm{OH}$ groups coordinated to $\mathrm{Eu}^{3+}$ ions, which are strong deactivators of their luminescence. The very interesting ability of the phosphine oxides with aromatic constituents to act as antennae in energy transfer was outlined.

Another example of the use of $\mathrm{Eu}^{3+}$ as a probe in a mesostructured material can be found in ref. 26 in which mesostructured silica thin films functionalized with hydrophobic organosilylated quinizarin derivatives are prepared via evaporation induced self-assembly (EISA). Incorporation of $\mathrm{Eu}^{3+}$ is performed by post-reacting the functionalized layers with several europium precursors. Unambiguous location of the quinizarin moieties inside the pores and their accessibility to $\mathrm{Eu}^{3+}$ ions are demonstrated using XRD, SAXS and fluorescence measurements. In these systems, an energy transfer between the grafted organic dye and the lanthanide was observed, thus reducing the fluorescence of quinizarin. The luminescence intensity of $\mathrm{Eu}^{3+}$ can be tuned by varying the nature of the lanthanide precursor, the mesophase and the chelate itself. The resulting optical responses differ with respect to concentration, lifetime and local environment of $\mathrm{Eu}^{3+}$ inside the thin films. Additionally, efficient energy transfer from $\mathrm{Tb}^{3+}$ to $\mathrm{Eu}^{3+}$ and electronic coupling probed by EPR between $\mathrm{Cu}^{2+}$ cations trapped in such mesoporous hybrid films give strong evidence of the presence of several metal ions per pore.

In ref. 53 luminescence of $\mathrm{Eu}^{3+}$ ions has also proved to be a useful local probe, in particular to investigate the possible interactions of the active species with the sol-gel matrix. The presence of two site distributions was evidenced in the studied hybrid compounds: most presumably, one is related to $\mathrm{Eu}^{3+}$ ions without $\mathrm{OH}$ groups in their first coordination sphere and the other to $\mathrm{Eu}^{3+}$ ions with $\mathrm{OH}$ groups in their direct environment. The relatively high emission intensities of $\mathrm{Eu}^{3+}$ activated $\left(\mathrm{EuH}_{i}\right)$ hybrid samples $(i=1-4)$, especially $\mathrm{EuH}_{2}$ and $\mathrm{EuH}_{3}$ (the luminescence intensity of the organic complex is retained up to $85 \%$ in the hybrid samples), in addition to their improved thermal stability as compared to organic molecules (up to $300{ }^{\circ} \mathrm{C}$ in air), opens the possibility of making organicinorganic hybrid phosphors usable for example in display or lighting devices while, until now, only pure inorganic compounds were used for such applications.

Table 1 shows a summary of the functional organosilanes that have been used to complex lanthanide ions in mesostructured hybrid materials. It must be said that this research 
Table 1 Functional organosilanes that have been used to complex lanthanide ions in mesostructured hybrid materials Ref. 107 and 108

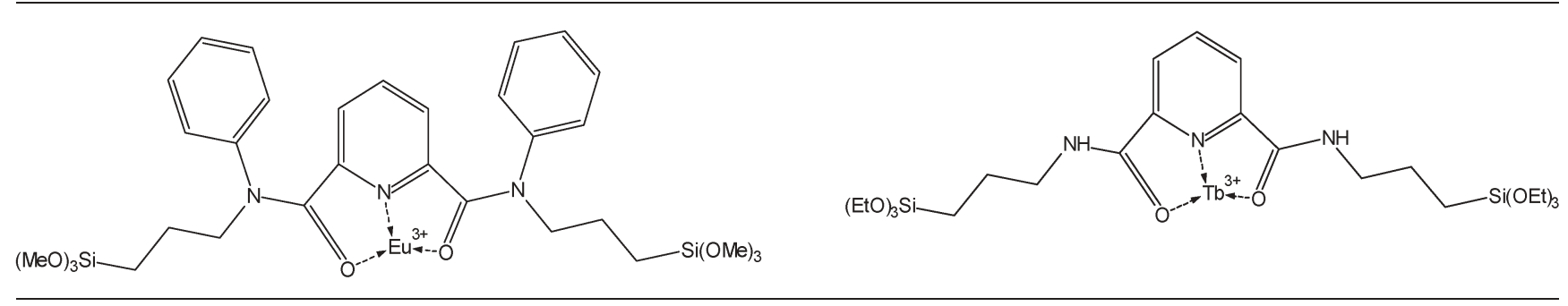<smiles>CCOCCCCNC(=O)N(C(=O)NCCCOCC)c1cc2ccc[n+]3[Z17][n+]4cccc1c4c23</smiles><smiles></smiles>

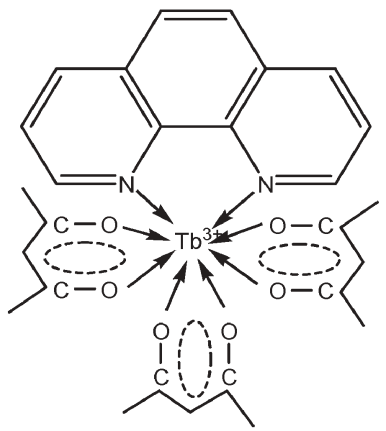

field has just emerged, and represents a great alternative not only to understand mechanisms of structure formation but also to develop new functional photonic devices.

\subsection{Lanthanide-doped hybrid materials as sensors in biological media}

In the past 20 years, lanthanide compounds have been widely investigated in the areas of life science, biotechnology and clinical diagnostics. In particular, the application of lanthanide fluorescence probes has been focused on time-resolved fluoroimmunoassays, DNA hybridization assays and fluorescence imaging microscopy. The suitability of lanthanide ions as bio-markers relies on their unique luminescence properties: (i) high photostability, (ii) long decay rates (from upper nanoto milli-second range) that allow time-gate detection, (iii) small
Stokes shifts, and (iv) narrow emission bands, that make these ions very well suited for elaboration of highly luminescent and photostable probes. These conditions, together with being soluble in the biological media, are the most important requirements for biological applications, as specified for example in the article by Soini and Hemmilä in 1979. ${ }^{111}$

The use of lanthanides in these areas has arisen as an alternative to overcome some of the limitations of traditional fluorescent biolabels such as organic dyes or more recently studied quantum dots. The main problems that organic dyes give rise to are the broad spectral features, short lifetime, photobleaching and potential toxicity to cells. However, the combination in the same object of a multitude of organic dyes with luminescent species, like lanthanide ions, ${ }^{112}$ as well as their encapsulation in inorganic matrices (such as silica nanoparticles, ${ }^{113}$ gold nanoparticles ${ }^{114}$ or silver nanoparticles), ${ }^{115}$ 

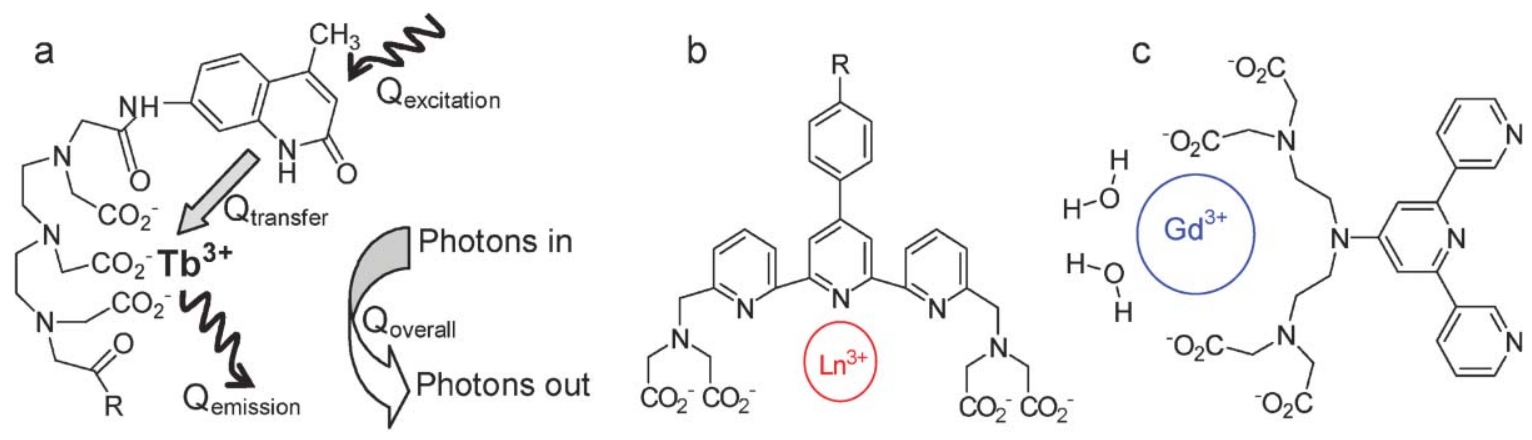

Fig. 8 (a) Energy pathway in lanthanide chelates with antenna effects. (b) General structure of typical fluorescent lanthanide chelate composed of terpyridine antenna part, polycarboxylate complexing part and emissor lanthanide ion. (c) A gadolinium chelate used as biolabel.

should constitute a promising strategy for achieving the preparation of ultrasensitive and highly photostable luminescent probes.

In the case of the well-known semiconductor quantum dots $(\mathrm{CdS}, \mathrm{CdSe}, \mathrm{ZnS}, \mathrm{CdSeTe} .$.$) that present a strong emission,$ they show more photostability and sharper spectral peaks than typical organic dyes. But a serious concern is to avoid aggregation and non specific adsorption of quantum dots (QDs) in the biological medium. Therefore, numerous studies have been devoted to solving these problems by designing versatile coreshell architectures combining diverse functionalities and surface modification into a single hybrid nanocomposite as biosensing platforms ${ }^{116-120}$ for application in in vivo imaging, diagnostics, targeting, therapy, etc. Although an appropriate coverage of the nanoparticles with shells can seal the pernicious $\mathrm{Cd}^{2+}, \mathrm{Se}^{2-}$-containing core, QDs are not completely innocuous, but a safe range likely exists in which they can accomplish their task without major interference with cell viability. ${ }^{121}$

The use of QDs seems to be restricted to fluorescent labeling, whereas highly luminescent lanthanide-based nanophosphors by combining the various properties of the lanthanide ions and/or the hybrid component should ensure several functions, enlarging their applications field.

In the past decade, a wide range of lanthanide-containing systems have been developed, including systems with lanthanide chelates, nanophosphors where the lanthanide ions are found at the doping level and those where lanthanide ions constitute the main component (oxides, fluorides, phosphates, etc.). However, before these systems can be used as biolabels, they must maintain three properties under aqueous biological conditions: efficient fluorescence, colloidal stability, and low non specific adsorption. ${ }^{11}$

Some of the most striking systems in terms of architecture design, easy synthesis, and multifunctional applications ${ }^{122}$ are summarized below.

Lanthanide chelates have been studied since the $1990 \mathrm{~s}^{123-125}$ as extremely promising luminescence probes for distance measurements using luminescence resonance energy transfer techniques. Chelated lanthanide labels offer enhancement of the molar absorption coefficients of the lanthanides by the donor units, as already mentioned (see Fig. 8a). Besides its function as a donor, chelators provide a protection towards water and dissolved oxygen coordination (assuring long-lived emission), as well as anchoring points for other reactive groups. In this way, they are excellent fluorescent tracers, can be stable in aqueous media and their long lifetime avoids reduction of the non specific background interference that appears in environmental and biological samples.

The majority of the studies involving lanthanide(III) complexes as luminescent bio-markers have dealt with thermodynamically stabilized complexes of anionic polychelating ligands such as $\beta$-diketones, polycarboxylates (EDTA, DTPA), aromatic amine derivates (pyridine, bipyridine, terpyridine, phenanthroline) or macrocycles. ${ }^{126-128}$ A general structure of typical fluorescent lanthanide chelates for bioanalytical assays is shown in Fig. 8b, that consists on a terpyridine group and complexing polycarboxylates. One concrete example of a biolabel with gadolinium is shown in Fig. 8c. Indeed, europium chelated with a derivate of diethylenetriaminetetraacetic acid (DTTA) which contains an isothiocyanate group for interaction with lysine residues is commercially available as DELFIA $\AA^{129}$ Europium Labeling Kit through Perkin Elmer.

An example of how lanthanide labels works in a timeresolved fluorescence DNA hybridization assay is shown in Fig. 9. ${ }^{130}$ The assay is based on two DNA probes labeled with a bidentate $\beta$-diketone on the 3 -terminus and EDTA$\mathrm{Eu}^{3+}$ complex on the 5-terminus. The two DNA probes are

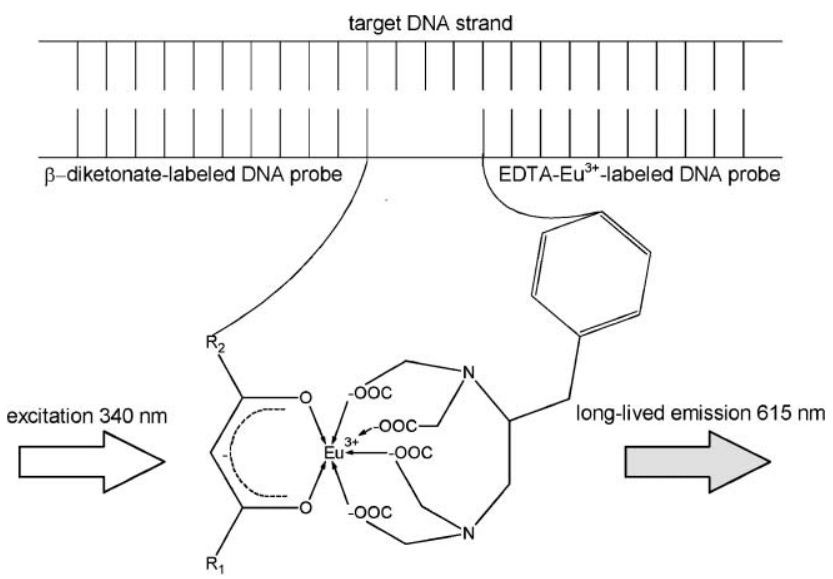

Fig. 9 Principle of the homogeneous time-resolved fluorescence DNA hybridization assay by DNA-mediated formation of an EDTA-Eu ${ }^{3+} \beta$-diketonate ternary complex (modified from ref. 130). 
complementary to the contiguous regions of a target DNA. After the hybridization of two DNA probes with the target sequence in a homogeneous solution, $\beta$-diketone and EDTA$\mathrm{Eu}^{3+}$ come close to each other to form a strongly fluorescent EDTA-Eu ${ }^{3+} \beta$-diketonate ternary complex, thus the target DNA can be directly detected by time-resolved fluorescence measurement. This assay format gives the detection limit of 6 pM for a target DNA.

Furthermore, dual lanthanide probes have been designed in order to assemble different properties in a unique platform, such as $\mathrm{Tb}^{3+}$ (luminophore)/ $\mathrm{Gd}^{3+}$ (paramagnetic contrastophore) chelates. ${ }^{131}$

One of the recent trends in the field of lanthanide chelates has been their inclusion in nanobeads composed of latex, ${ }^{132-135}$ silica $^{136-138}$ and titania ${ }^{139}$ inorganic host materials, or plasmonresonant nanoparticles, PRPs (Ag). ${ }^{140}$ The objective of these entrapments is to develop hybrid materials with improved thermal, mechanical and chemical stability; as well as, in terms of luminescence, the aim to enhance lanthanide emission, combine lanthanide luminescence with other optical processes (surface plasmon resonance) and allow surface modification for grafting bio-active molecules (molecular recognition, drugs, immobilization agents, etc.). Most of them are synthesized by covalent binding copolymerization in oil-water microemulsions ${ }^{141}$ since direct synthesis based on hydrolysis and condensation of metal alkoxides in aqueous alcohol solutions tends to agglomerate the particles by electrostatic, van der Waals and short-range repulsive interaction potentials.

The versatility of lanthanide chelates offers huge possibilities of combination with different types of functional elements for application in the life science field. However, chelation chemistry is often expensive and complex, and novel and simpler biolabels have been investigated such as lanthanide oxide and fluoride $\left(\mathrm{Ln}_{2} \mathrm{O}_{3}, \mathrm{LnF}_{3}\right)$ nanoparticles, lanthanidedoped nanophosphors and more complex and multifunctional structured hybrid materials containing lanthanide nanoparticles (core-shell architectures and specific functionalization).

For biological applications, the morphology of the nanoparticles is of key importance: they must be comparable in size and chemically compatible with biomolecules such as enzymes, proteins, antibodies, DNA, etc. Furthermore, since natural or untreated $\mathrm{Ln}_{2} \mathrm{X}_{3}$ or $\mathrm{LnX}_{3}(\mathrm{X}=\mathrm{O}, \mathrm{F}$, respectively) nanoparticles are insoluble in water and easily dissolved by acids during activation and conjugation, they can lose their optical properties. As a consequence, protective coatings of nanoparticles containing appropriate functional groups on their surfaces can avoid these problems and facilitate binding with biomolecules.

Feng et al. ${ }^{142}$ synthesized nanoparticles based on $\mathrm{Eu}_{2} \mathrm{O}_{3}$, $\mathrm{Gd}_{2} \mathrm{O}_{3}, \mathrm{Nd}_{2} \mathrm{O}_{3}, \mathrm{Eu}: \mathrm{Y}_{2} \mathrm{O}_{3}, \mathrm{Eu}: \mathrm{Gd}_{2} \mathrm{O}_{3} \ldots$ by a gas-phase and spray pyrolysis technique, which is a simple and highly efficient method that allows functionalization of the particles during the synthesis. For example, amino-functionalized silica capped- $\mathrm{Eu}_{2} \mathrm{O}_{3}$ nanoparticles for atrazine immunoassay with good sensitivity, avidin-coated $\mathrm{Eu}: \mathrm{Gd}_{2} \mathrm{O}_{3}$ nanoparticles for the visualization of protein micropatterns ${ }^{143}$ and or poly-lysinecoated Eu: $\mathrm{Gd}_{2} \mathrm{O}_{3}$ nanoparticles for phenoxybenzoic acid immunoassays ${ }^{144}$ have been recently studied.
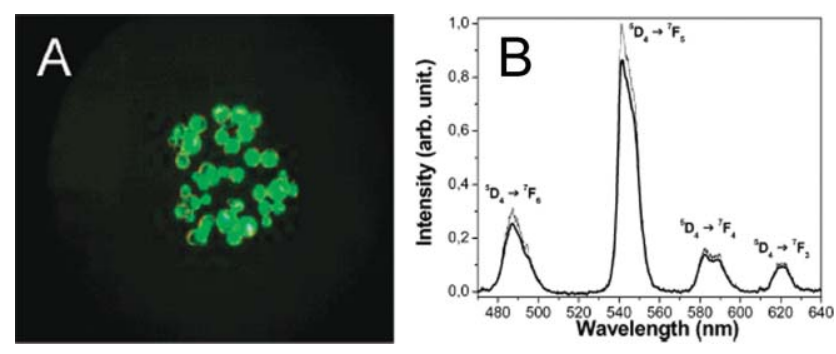

Fig. 10 (a) Fluorescent micrograph showing the detection of oligonucleotides using the $\mathrm{Gd}_{2} \mathrm{O}_{3}: \mathrm{Tb} @ \mathrm{SiO}_{x}$-FITC nanoparticles, and (b) emission spectra of polysiloxane-coated $\mathrm{Gd}_{2} \mathrm{O}_{3}: \mathrm{Tb}$ colloids.

Another synthetic method for preparing potentially interesting Ln-doped $\mathrm{Y}_{2} \mathrm{O}_{3}$, and $\mathrm{Gd}_{2} \mathrm{O}_{3}$ nano-oxides as biolabels is direct precipitation using polyols. ${ }^{145,146}$ Tillement and coworkers have developed multifunctional $\mathrm{Gd}_{2} \mathrm{O}_{3}$ nanoparticles doped by $\mathrm{Tb}^{3+}$ ions and protected by a silica shell containing covalently linked fluorescein $\left(\mathrm{Gd}_{2} \mathrm{O}_{3}: \mathrm{Tb} @ \mathrm{SiO}_{x^{-}}\right.$ FITC, where FITC is fluorescein isothiocyanate) and coated by biotargeting groups such as oligonucleotide $(\mathrm{cT})_{22}$ or streptavidin (SAV). ${ }^{19}$ The use of these nanoparticles appears to be a promising alternative to the lipid vesicles containing gadolinium complexes (see Fig. 10).

In the same way, well-dispersed colloids of nanophosphors such as Eu-doped $\mathrm{YVO}_{4}{ }^{147,148}$ capped with silica hybrid coatings have been prepared from precipitation in aqueous solution. These nanoparticles functionalized with guanidinium groups act as artificial toxins and specifically target sodium channels. They are individually detectable in live cardiac myocytes, revealing the distribution of sodium channels. A schematic representation of the hybrid lanthanide structure is presented in Fig. 11, as well as its emission spectrum and widefield fluorescence microscopy of individual nanoparticles.

$\mathrm{Ln}^{3+}$-doped phosphates have also been envisaged as potential biolabels. For example, the use of Eu-doped apatitic tricalcium phosphate has been examined as a biological probe for observing the traffic of grafted biomolecules since they are internalizable by human epithelial cells. ${ }^{149}$ Another example can be the $\mathrm{LaPO}_{4}: \mathrm{Ce} / \mathrm{Tb}$ nanoparticles with streptavidin prepared by Carusso for biotin-streptavidin binding studies. ${ }^{150}$

Down and up-converting and near-infrared (NIR)-emitting biolabels with a silica coating would be beneficial because these materials can be excited at wavelengths at which biomolecules do not absorb, and thus minimizing the loss of excitation energy to the surrounding material.

Emission in the NIR region can minimize interferences from, for instance, the autofluorescence of proteins. To date, only a few reports have dealt with lanthanide-based nanoparticles with near-infrared emitting lanthanides, such as neodymium, erbium, praseodymium, holmium, and ytterbium. ${ }^{151,152}$

Lanthanide ions exhibit efficient energy down and upconversion emission properties. The downconversion process is the conversion of higher energy photons into lower energy photons, meanwhile upconversion processes convert lower energy photons (i.e. infrared excitation light) into higher energy photons (emission at visible wavelengths) via the sequential absorption and energy transfer steps. 

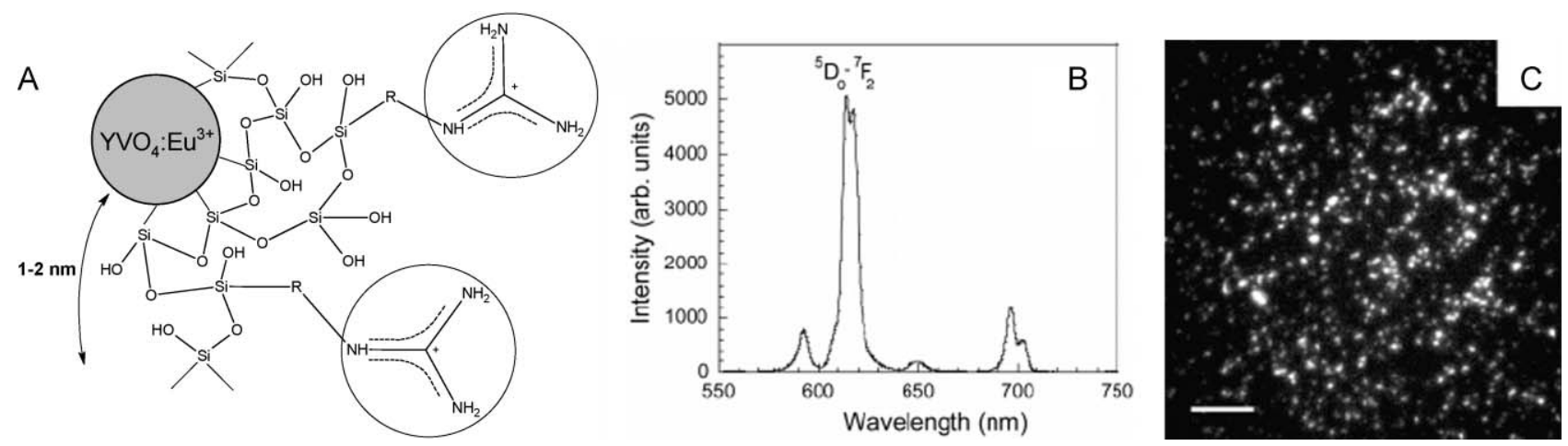

Fig. 11 (a) Schematic representation of a $\mathrm{YVO}_{4}$ :Eu nanoparticle functionalized with guanidinium groups, (b) emission spectrum and (c) wide-field fluorescence microscopy of individual nanoparticles.
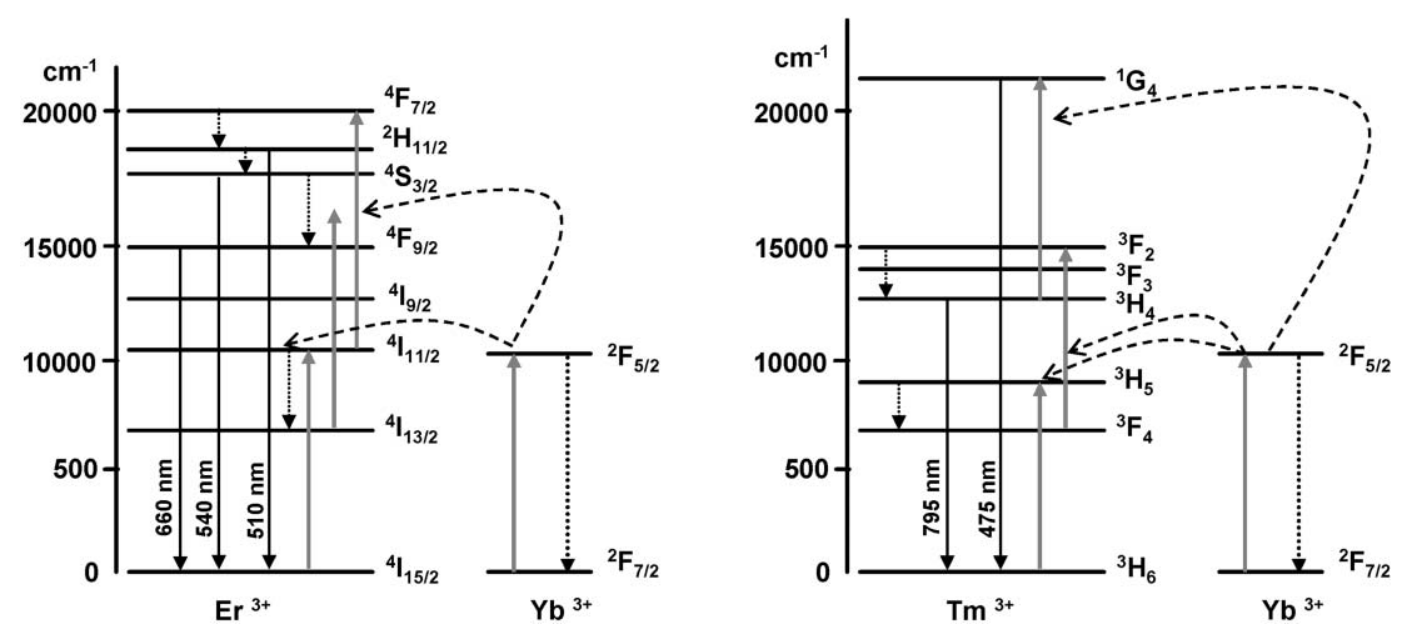

Fig. 12 Upconversion mechanism for $\mathrm{Er}^{3+} / \mathrm{Tm}^{3+} / \mathrm{Yb}^{3+}$ ions (based on ref. 155).

There are only a reduced number of studies about lanthanide-based biolabels that emit in the visible region by either upconversion or downconversion processes. For example, very small $(20 \mathrm{~nm})$ nanoparticles of fluorescent $\mathrm{Eu}^{3+}$-doped $\mathrm{LaF}_{3}$ for intracellular labeling have been prepared by coprecipitation with a natural biopolymer, chitosan. ${ }^{153}$ In the report of Holm and coworkers ${ }^{154}$ a special mention is given to upconverting nanophosphors of $\mathrm{Er} / \mathrm{Yb}-\mathrm{Y}_{2} \mathrm{O}_{3}, \mathrm{Er}-\mathrm{Y}_{2} \mathrm{O}_{3}$ and $\mathrm{Tm} / \mathrm{Yb}-\mathrm{Y}_{2} \mathrm{O}_{3}$ encapsulated into a silica shell with emission in the red $(640 \mathrm{~nm})$, green $(550 \mathrm{~nm})$ and blue $(480 \mathrm{~nm})$ regions respectively. Recently, Sivakumar and coworkers have described the preparation of nearly monodisperse (40 nm) silica coated $\mathrm{Ln}^{3+}$-doped $\mathrm{LaF}_{3}$ nanoparticles and their biological conjugation to FITC-avidin. A wide range of emission lines ( $\lambda=450$ to $1650 \mathrm{~nm}$ ) by up and downconversion processes have been achieved by doping with different lanthanide ions $\left(\mathrm{Tb}^{3+}\right.$, $\mathrm{Eu}^{3+}, \mathrm{Nd}^{3+}, \mathrm{Er}^{3+}, \mathrm{Yb}^{3+}$ and $\left.\mathrm{Tm}^{3+}\right) .{ }^{155}$ The upconversion mechanism for $\mathrm{Er}^{3+} / \mathrm{Tm}^{3+} / \mathrm{Yb}^{3+}$ ions is shown in Fig. 12.

One beautiful example of nanoprobes with near-IR persistent luminescence for in vivo imaging is that presented by Masne-de-Chermont et al. ${ }^{152}$ They consist of sol-gel prepared nanoparticles of $\mathrm{MgSiO}_{3}$ doped with $\mathrm{Eu}^{2+}, \mathrm{Dy}^{3+}$ and $\mathrm{Mn}^{2+}$ which give persistent luminescence. Chemical modification of the nanoparticles' surface by appropriate biocompatible polymers such as polyethyleneglycol led to lung or liver targeting or to long-lasting blood circulation. These nanohybrids are suitable for small animal imaging because they can be excited before injection and follow their in vivo distribution for more than $1 \mathrm{~h}$ without the need for any external illumination source. Tumor mass could also be identified on a mouse model, as shown in Fig. 13.

Another representative example of phosphor is Sm-doped $\mathrm{Gd}_{2} \mathrm{O}_{3}$ nanoparticles, with potential use in dual upconversion

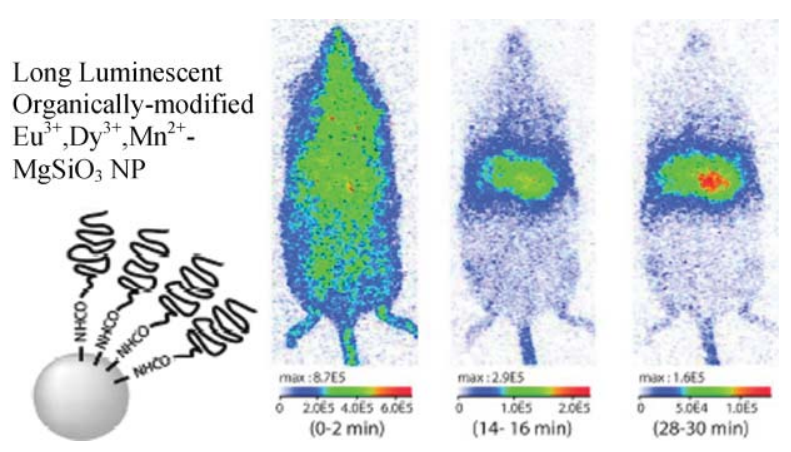

Fig. 13 Example of persistent luminescent surface-modified nanoparticles suitable for small animal imaging. The images show in vivo biodistristribution of carboxyl-functionalized nanoparticles (NPs) with a preinjection of anionic liposomes $(6 \mu \mathrm{mol}, 100 \mu \mathrm{l}) 5 \mathrm{~min}$ before NP injection. 
fluorescence and magnetic resonance imaging (MRI) applications since Gd is a known MRI contrast agent. ${ }^{156}$

More sophisticated multifunctional systems have been recently developed. This is the case of magnetic/luminescent core-shell particles for their application in immunoassays with an internal standard. Several reports can be found in the literature, most of them based on spherical particles containing magnetic iron oxide cores. Dosev and coworkers have developed a system with cobalt and neodymium-doped iron oxide and luminescent shells of europium-doped gadolinium oxide $\left(\mathrm{Eu}: \mathrm{Gd}_{2} \mathrm{O}_{3}\right) \cdot{ }^{157}$ Furthermore, superparamagnetic $\mathrm{Fe}_{3} \mathrm{O}_{4}$ nanoparticles have been trapped in silica spheres including $\mathrm{Tb}^{3+}$-complexes in the shell. ${ }^{158}$

Another interesting example consists of hybrid nanoparticles possessing magnetic response, upconversion fluorescence and bioaffinity. ${ }^{159}$ They were prepared by coprecipitation of $\mathrm{NaYF}_{4}: \mathrm{Yb}, \mathrm{Er}$ up-converting phosphors (red/green fluorescence) on superparamagnetic nanoparticles (iron oxide) and subsequently coated with silica and immobilized with streptavidin (see Fig. 14). They can be use for immobilization of biotinylated biomolecules and capture of target molecules in samples.

A last example that we find interesting to underline is the combination of lanthanide-based phosphors with plasmonresonant nanoparticles used as single target molecule detectors. ${ }^{160}$ In this field, Aslan has designed highly versatile core-shell $\mathrm{Ag} @ \mathrm{SiO}_{2}$ nanocomposites which allow the researcher to incorporate fluorescent lanthanide ions to the outer silica shell, giving an enhancement of the fluorescent signal and a huge increase in particle detectability. ${ }^{161}$

\section{Conclusions}

Research in to functional hybrid organic-inorganic materials is being mostly supported by the growing interest of chemists, physicists, biologists and materials scientists to fully exploit this opportunity for creating smart hybrid materials taking benefit from the best of the three realms: inorganic, organic and biological. Even bio-inspired strategies are used to "mimic" the growth processes occurring in biomineralization and design innovative multiscale structured hybrids are emerging. ${ }^{162}$ Organic-inorganic hybrid materials do not represent only a creative alternative to designing new materials and compounds for academic research, but also their improved or unusual features allow the development of innovative industrial applications. ${ }^{163}$ Active optical applications of hybrid nanocomposites might present the most attractive field to realise applications for the 21 st century. Indeed, the exploitation of active optical properties of photoactive coatings and systems is strongly emerging. Some hybrid products have already entered the applied field. Examples include the one million TV sets sold annually by Toshiba, the screens of which are coated with hybrids made of indigo dyes embedded in a silica-zirconia matrix, ${ }^{164}$ organically doped sol-gel glassware sold by Spiegelau. ${ }^{165,166}$ Other reported examples in the past years include hybrid materials having excellent laser efficiencies and good photostability, ${ }^{167}$ very fast photochromic response, ${ }^{168}$ very high and stable second order non-linear optical response, ${ }^{169}$ or being original $\mathrm{pH}$ sensors, ${ }^{170}$ electroluminescent diodes ${ }^{171}$ or hybrid liquid crystals. ${ }^{172}$

Because of their high versatility in chemical, physical properties and shaping, lanthanide-based hybrid nanocomposites will open a land of promising applications in many fields where their extraordinary optical and magnetic properties could be fully exploited. Out looking for new developments we should mention the interesting materials reporting photoluminescence by using a new family of microporous hybrid organic-inorganic materials with metal-organic frameworks. ${ }^{173,174}$ These crystalline supramolecular structures with

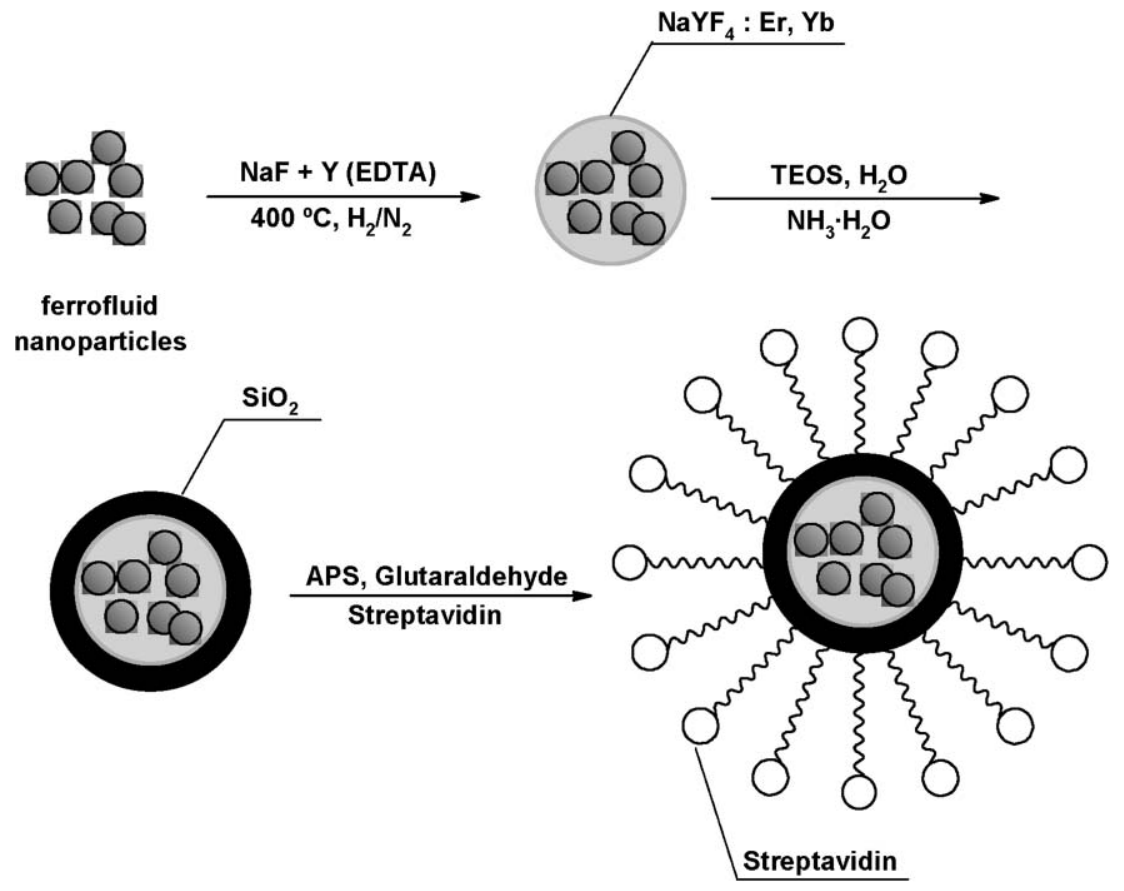

Fig. 14 Procedure for the preparation of streptavidin immobilized upconversion fluorescent magnetic nanoparticles. 
well-defined structures and tunable location of the lanthanide ions will provide better understanding of luminescence properties of lanthanide hybrid organic-inorganic hybrid materials. ${ }^{175,176} \mathrm{We}$ also want to emphasize that luminescent lanthanide-doped hybrid materials will find applications in the areas of photonics, life science, biotechnology and clinical diagnostics. More specifically new developments on: microoptical devices and luminescent waveguides, smart functional windows, sensors and bio-sensors based on time-resolved fluoroimmunoassays, DNA hybridation assays, fluorescence imaging microscopy, CT tomography, fluorescent coatings (with $\mathrm{Tb}^{3+}, \mathrm{Pr}^{3+}, \mathrm{Eu}^{3+}$ ) for $\mathrm{CT}$ tomography with X-rays of low energy, small animal in vivo imaging by using hybrid nanoprobes with near infrared luminescence ${ }^{152}$ will appear soon.

\section{Acknowledgements}

Financial support has been provided by Spanish Ministerio de Education y Ciencia (MEC, project MAT-2005-00541). B. Julián and J. Planelles thank for personal financial support "Ramon y Cajal" Program and FPU Fellowship. The support given by FAME European Network of Excellence is also recognised (B. Julián and C. Sanchez).

\section{References}

1 G. Blasse and B. C. Grabmaier, Luminescent Materials, Springer, Berlin, 1994, p. 65.

2 R. Reisfeld, J. Alloys Compd., 2004, 374, 6.

3 J. M. Lehn, Angew. Chem., 1990, 102, 1347.

4 G. F. de Sá, O. L. Malta, C. M. de Donegá, A. M. Simas, R. L. Longo, P. A. Santa-Cruz and F. da Silva, Jr., Coord. Chem. Rev., 2000, 196, 165.

5 R. F. de Farias and C. Airoldi, Colloids Surf., A, 2000, 172, 145.

6 W. Strek, J. Sokolnicki, J. Legendziewicz, K. Maruszewski, R. Reisfeld and T. Pavich, Opt. Mater., 1999, 13, 41.

7 R. Reisfeld, Struct. Bonding, 1996, 85, 215.

8 O. Wolfbeis, R. Reisfeld and I. Oehme, Struct. Bonding, 1996, $\mathbf{8 5}, 51$.

9 R. Reisfeld, Struct. Bonding, 1996, 85, 99.

10 D. Avnir, D. Levy and R. Reisfeld, J. Phys. Chem., 1984, 88, 5956.

11 (a) Y. Wada, T. Okubo, M. Ryo, T. Nakazawa, Y. Hasegawa and S. Yanagida, J. Am. Chem. Soc., 2000, 122, 8583; (b) N. Sabbatini, M. Guardigli and J.-M. Lehn, Coord. Chem. Rev., 1993, 123, 201.

12 N. Sabatini, S. Dellonte, M. Ciano, A. Bonazzi and V. Balzani, Chem. Phys. Lett., 1984, 107, 212.

13 H. Maas, A. Currao and G. Calzaferri, Angew. Chem., Int. Ed., 2002, 41, 2495.

14 F. J. Duarte, Appl. Opt., 1994, 33, 3857.

15 F. J. Duarte, A. Costela, I. Garcia-Moreno, R. Sastre, J. J. Ehrlich and T. S. Taylor, Opt. Quantum Electron., 1997, 29, 461.

16 F. J. Duarte, Opt. Commun., 1995, 117, 480.

17 F. J. Duarte, Appl. Opt., 1999, 38, 6347.

18 C. Sanchez and F. Ribot, New J. Chem., 1994, 18, 1007.

19 C. Louis, R. Bazzi, C. A. Marquette, J. L. Bridot, S. Roux, G. Ledoux, B. Mercier, L. Blum, P. Perriat and O. Tillement, Chem. Mater., 2005, 17, 1673.

20 M. Yu, J. Lin and J. Fang, Chem. Mater., 2005, 17, 1783.

21 M. Tan, Z. Ye, G. Wang and J. Yuan, Chem. Mater., 2004, 16, 2494.

22 G.-S. Yi and G.-M. Chow, Chem. Mater., 2007, 19, 341.

23 C. T. Kresge, M. E. Leonowicz, W. J. Roth, J. C. Vartuli and J. S. Beck, Nature, 1992, 359, 710.

24 L. Nicole, C. Boissière, D. Grosso, A. Quach and C. Sanchez, J. Mater. Chem., 2005, 15, 3598.

25 R. Hernandez, A.-C. Franville, P. Minoofar, B. Dun and J. I. Zink, J. Am. Chem. Soc., 2001, 123, 1248.
26 A. Quach, V. Escax, L. Nicole, P. Goldner, O. Guillot-Noël, P. Aschehoug, P. Hesemann, J. Moreau, D. Gourier and C. Sanchez, J. Mater. Chem., 2007, 24, 2552.

27 L. A. Riseberg and M. J. Weber, in Progress in Optics, ed. E. Wolf, Elsevier, Amsterdam, Vol. XIV.

28 O. Malta, J. Lumin., 1997, 71, 229.

29 A. F. Campos, A. Meijerink, C. de Mello Donegá and O. L. Malta, J. Phys. Chem. Solids, 2000, 61, 1489.

30 W. M. Faustino, O. L. Malta and G. F. de Sa, J. Chem. Phys., 2005, 122, 054109.

31 (a) J.-C. G. Bunzli, in Spectroscopic Properties of Rare Earths in Optical Materials, ed. G. Liu and B. Jacquier, Springer, Berlin; (b) S. Petoud, J.-C. G. Bünzli, T. Glanzman, C. Piguet, Q. Xiang and R. P. Thummel, J. Lumin., 1999, 82, 69.

32 N. Sato and S. Shinkai, J. Chem. Soc., Perkin Trans. 2, 1993, 2, 621.

33 P. Dorenbos, J. Phys.: Condens. Matter, 2003, 15, 8417.

34 S. S. Nobre, P. P. Lima, L. Mafra, R. A. Sa Ferreira, R. O. Freire, L. Fu, U. Pischel, V. De Zea Bermudez, O. L. Malta and L. D. Carlos, J. Phys. Chem. C, 2007, 111, 3275.

35 (a) Sol-Gel Optics I, ed. J. D. Mackenzie and D. R. Ulrich, SPIE, Washington, 1990, p. 1328; (b) Sol-Gel Optics II, ed. J. D. Mackenzie, SPIE, Washington, 1992, p. 1758; (c) Sol-Gel Optics III, ed. J. D. Mackenzie, SPIE, Washington, 1994, p. 2288; (d) Sol-Gel Optics IV, ed. J. D. Mackenzie, SPIE, Washington, 1997, p. 3136; (e) Organic-Inorganic Hybrids for Photonics, ed. L. Hubert and S. I. Najafi, SPIE, Washington, 1998, 3469; (f) Sol-Gel Optics V, ed. B. S. Dunn, E. J. A. Pope, H. K. Schmidt and M. Yamane, SPIE, Washington, 2000, 3943; (g) Hybrid Organic-Inorganic Composites, ed. J. E. Mark, C. Y. C. Lee and P. A. Bianconi, American Chemical Society, Washington, 1995; (h) B. Dunn and J. I. Zink, J. Mater. Chem., 1991, 1, 903 .

36 (a) C. Sanchez and B. Lebeau, Mater. Res. Bull., 2001, 26, 377; (b) C. Sanchez, G. J. de A. A. Soler-Illia, F. Ribot, T. Lalot, C. R. Mayer and V. Cabuil, Chem. Mater., 2001, 13, 3061-3083; (c) B. Lebeau and C. Sanchez, Curr. Opin. Solid State Mater. Sci., 1999, 4, 11.

37 J.-P. Boilot, F. Chaput, T. Gacoin, L. Malier, M. Canva, A. Brun, Y. Lévy and J.-P. Galaup, C. R. Acad. Sci., 1996, 322, 27.

38 D. Avnir, S. Braun, O. Lev, D. Levy and M. Ottolenghi, in SolGel Optics, Processing and Applications, ed. L.C. Klein, Kluwer Academic Publishers, 1994, 539.

39 (a) D. Levy and D. Avnir, J. Phys. Chem., 1988, 9, 4734; (b) D. Levy, S. Einhorn and D. Avnir, J. Non-Cryst. Solids, 1989, $113,137$.

40 (a) E. Cordoncillo, F. J. Guaita, P. Escribano, C. Philippe, P. Aschehoug, B. Viana and C. Sanchez, J. Sol-Gel Sci. Technol., 2003, 26, 977; (b) E. Cordoncillo, F. J. Guaita, P. Escribano, C. Philippe, B. Viana and C. Sanchez, Opt. Mater., 2001, 18, 309.

41 T. Keeling-Tusker and J. D. Brennan, Chem. Mater., 2001, 13, 3331

42 F. J. Duarte, A. Costela, I. Garcia-Moreno and R. Sastre, Appl. Opt., 1999, 39, 6522 .

43 A. Costela, I. Garcia-Moreno and R. Sastre, in Handbook of Advanced Electronic and Photonic Materials: Liquid Crystals, Display and Laser Materials, ed. H.S. Nalwa, Academic, New York, 2001.

44 W. Holzer, H. Gratz, T. Schmitt, A. Penzkofer, A. Costela, I. Garcia-Moreno, R. Sastre and F. J. Duarte, Chem. Phys., 2000, 256, 125 .

45 A. C. Franville, D. Zambon, R. Mahiou, S. Chou, Y. Troin and J. C. Cousseins, J. Alloys Compd., 1998, 275-277, 831.

46 A. C. Franville, D. Zambon, R. Mahiou and Y. Troin, Chem. Mater., 2000, 12, 428.

47 C. Sanchez, B. Lebeau, F. Chaput and J.-P. Boilot, Adv. Mater., 2003, 15(23), 1969.

48 (a) B. Julián, R. Corberán, El Cordoncillo, P. Escribano, B. Viana and C. Sanchez, J. Mater. Chem., 2004, 14, 3337; (b) B. Julian, H. Beltran, E. Cordoncillo, P. Escribano, B. Viana and C. Sanchez, J. Sol-Gel Sci. Technol., 2003, 26, 977.

49 E. Cordoncillo, P. Escribano, B. Viana and C. Sanchez, J. Mater. Chem., 1998, 8, 807. 
50 E. Cordoncillo, J. Carda, H. Beltrán, F. J. Guaita, A. Barrio, P. Escribano and C. Sanchez, Bol. Soc. Esp. Ceram. Vidrio, 2000, 39, 95 .

51 N. I. Koslova, B. Viana and C. Sanchez, J. Mater. Chem., 1993, 3, 111.

52 M. Trejo-Valdez, P. Jenouvrier and M. Langlet, J. Non-Cryst. Solids, 2004, 345\&346, 628.

53 A.-C. Franville, R. Mahiou, D. Zambon and J.-C. Cousseins, Solid State Sci., 2001, 3, 211.

54 P. Jenouvrier, E. Cela, C. Coutier, M. Langlet, R. Rimet and J. Fick, Appl. Phys. B, 2001, 73, 463.

55 X. L. Ji, B. Li, S. Jiang, D. Dong, H. J. Zhang, X. B. Jing and B. Z. Jiang, J. Non-Cryst. Solids, 2000, 275, 52.

56 R. A. Sá Ferreira, L. D. Carlos, R. R. Gonçalves, S. J. L. Ribeiro and V. de Zea Bermudez, Chem. Mater., 2001, 13, 2991.

57 H. J. Im, C. Willis, A. C. Stephan, M. D. Pawel, S. Saengkerdsub and S. Dai, Appl. Phys. Lett., 2004, 84, 2448.

58 (a) V. Z. Bermudez, L. D. Carlos, M. C. Duarte, M. M. Silva, C. J. R. Silva, M. J. Smith, M. Assunção and L. Alcacer, J. Alloys Compd., 1998, 275-277, 21; (b) V. de Zea Bermudez, L. D. Carlos and L. Alcacer, Chem. Mater., 1999, 11, 569.

59 T. Brankova, V. Bekiari and P. Lianos, Chem. Mater., 2003, 15, 1855.

60 L. S. Fu, R. A. Sá Ferreira, N. J. O. Silva, L. D. Carlos, V. de Zea Bermudez and J. Rocha, Chem. Mater., 2004, 16, 1507.

61 L. D. Carlos, V. de Zea Bermudez, R. A. Sá Ferreira, L. Marques and M. Assunção, Chem. Mater., 1999, 11, 581.

62 L. D. Carlos, R. A. Sá Ferreira, V. de Zea Bermudez and S. J. L. Ribeiro, Adv. Funct. Mater., 2001, 11, 111.

63 L. D. Carlos, R. A. Sá Ferreira, R. N. Pereira, M. Assunção and V. de Zea Bermudez, J. Phys. Chem. B, 2004, 108, 14924.

64 R. Moleski, E. Stathatos, V. Bekiari and P. Lianos, Thin Solid Films, 2002, 416, 279.

65 L. D. Carlos, R. A. Sá Ferreira, V. de Zea Bermudez, C. Molina, L. A. Bueno and S. J. L. Ribeiro, Phys. Rev. B, 1999, 60, 10042.

66 L. D. Carlos, R. A. Sá Ferreira and V. de Zea Bermudez, in Handbook of Organic-Inorganic Hybrid Materials and Nanocomposites, ed. H. S. Nalwa, American Scientific Publishers, California, 2003, vol. 1, ch. 9, pp. 353-380.

67 L. D. Carlos, Y. Messaddeq, H. F. Brito, R. A. Sá Ferreira, V. de Zea Bermudez and S. J. L. Ribeiro, Adv. Mater., 2000, 12, 594.

68 L. Fu, R. A. Sá Ferreira, N. J. O. Silva, A. J. Fernandes, P. Ribeiro-Claro, I. S. Gonçalves, V. de Zea Bermudez and L. D. Carlos, J. Mater. Chem., 2005, 15, 3117.

69 H. R. Li, L. S. Fu, J. Lin and H. J. Zhang, Thin Solid Films, 2002, 416, 197.

70 C. X. Du, L. Ma, Y. Xu and W. L. Li, J. Appl. Polym. Sci., 1997, 66, 1405.

71 W. Strek, J. Legendziewicz, E. Lukowiak, K. Maruszewski, J. Sokolnicki, A. A. Boiko and M. Borzechowska, Spectrochim. Acta, Part A, 1998, 54, 2215.

72 Q. M. Wang and B. Yan, J. Mater. Chem., 2004, 14, 2450.

73 P. Lenaerts, A. Storms, J. Mullens, J. D'Haen, C. GörllerWalrand, K. Binnemans and K. Driesen, Chem. Mater., 2005, 17, 5194.

74 K. Binnemans, P. Lenaerts, K. Driesen and C. Görller-Walrand, J. Mater. Chem., 2004, 14, 191.

75 P. Lenaerts, K. Driesen, R. Van Deun and K. Binnemans, Chem. Mater., 2005, 17, 2148.

76 P. Lenaerts, E. Ryckebosch, K. Driesen, R. Van Deun, P. Nockemann, C. Görller-Walrand and K. Binnemans, J. Lumin., 2005, 114, 77.

77 L. Armelao, G. Bottaro, S. Quici, M. Cavazzini, M. C. Raffo, F. Barigelletti and G. Accorsi, Chem. Commun., 2007, 2911.

78 J. H. Clark and D. J. Macquarrie, Chem. Commun., 1998, 8, 853.

79 J. Liu, X. Feng, G. E. Fryxell, L.-Q. Wang, A. Y. Kim and M. Gong, Adv. Mater., 1998, 10, 161 .

80 D. J. Macquarrie and D. B. Jackson, Chem. Commun., 1997, 18, 1781 .

81 L. Mercier and T. J. Pinnavaia, Adv. Mater., 1997, 9, 500.

82 K. Moller, T. Bein and R.-X. Fischer, Chem. Mater., 1998, 10, 1841 .

83 D. S. Shephard, W. Zhou, T. Maschmeyer, J. M. Matters, C. L. Roper, S. Parsons, B. F. G. Johnson and M. J. Duer, Angew. Chem., Int. Ed., 1998, 37, 2719.
84 T. Nguyen, J. Wu, V. Doan, B. Schwartz and S. Tolbert, Science, 2000, 288, 652.

85 T. Clark, J. D. Ruiz, H. Fan, C. J. Brinker, B. I. Swanson and A. N. Parikh, Chem. Mater., 2000, 12, 3879.

86 X. M. Guo, L. Fu, H. Zhang, L. D. Carlos, C. Peng, J. Guo, J. Yu, R. Deng and L. Sun, New J. Chem., 2005, 29, 1351.

87 S. Gago, J. A. Fernandes, J. P. Rainho, R. A. Sa Ferreira, M. Pillinger, A. A. Valente, T. M. Santos, L. D. Carlos, P. J. A. Ribeiro-Claro and I. S. Gonçalves, Chem. Mater., 2005, 17, 5077.

88 Q. Xu, L. Li, X. Liu and R. Xu, Chem. Mater., 2002, 14, 549.

89 L. Fu, H. Zhang and P. Boutinaud, J. Mater. Sci. Technol., 2001, 17, 293.

90 Q. G. Meng, P. Boutinaud, A. C. Franville, H. J. Zhang and R. Mahiou, Microporous Mesoporous Mater., 2003, 65, 127.

91 L. N. Sun, H. J. Zhang, C. Y. Peng, J. B. Yu, Q. G. Meng, L. S. Fu, F. Y. Liu and X. M. Guo, J. Phys. Chem. B, 2006, 110, 7249.

92 C. Y. Peng, H. J. Zhang, J. B. Yu, Q. G. Meng, L. S. Fu, H. R. Li, L. N. Sun and X. M. Guo, J. Phys. Chem. B, 2005, 109, 15278.

93 Y. Lu, R. Gangull, C. A. Drewlen, M. T. Anderson, C. J. Brinker, W. Gong, Y. Guo, H. Soyez, B. Dunn, M. H. Huang and J. I. Zink, Nature, 1997, 389, 364.

94 M. H. Huang, B. S. Dunn, H. Soyez and J. I. Zink, Langmuir, 1998, 14, 7331 .

95 M. H. Huang, H. Soyez, B. S. Dunn and J. I. Zink, Chem. Mater., $2000,12,231$

96 A. C. Franville, B. Dunn and J. I. Zink, J. Phys. Chem. B, 2001, 105, 10335

97 J. Wu, M. M. Abu-Omar and S. Tolbert, Nano Lett., 2001, 1, 27.

98 S. L. Burkett, S. D. Sims and S. Mann, Chem. Commun., 1996 1367.

99 B. Julián, J. Planelles, E. Cordoncillo, P. Escribano, P. Aschehoug, C. Sanchez, B. Viana and F. Pellé, J. Mater. Chem., 2006, 16, 4612.

100 R. J. P. Corriu, Angew. Chem., Int. Ed., 2000, 39, 1376.

101 J.-P. Bezombes, C. Chuit, R. J. P. Corriu and C. Reyé, J. Mater. Chem., 1998, 8, 1749.

102 (a) J.-P. Bezombes, C. Chuit, R. J. P. Corriu and C. Reyé, J. Mater. Chem., 1999, 9, 1727; (b) J.-P. Bezombes, C. Chuit, R. J. P. Corriu and C. Reyé, Can. J. Chem., 2000, 78, 1519.

103 D. R. Cousins and F. A. Hart, J. Inorg. Nucl. Chem., 1967, 29, 1745.

104 G. Valle, G. Casotto, P. L. Zanonato and B. Zarli, Polyhedron, 1986, 5, 2093.

105 J.-C. G. Bunzli and G. R. Choppin, in Lanthanide Probes in Life, Chemical, and Earth Sciences, Elsevier, New York, 1989.

106 F. Embert, A. Mehdi, C. Reyé and R. J. P. Corriu, Chem. Mater., 2001, 13, 4542

107 P. N. Minoofar, R. Hernandez, S. Chia, B. Dunn, J. I. Zink and A.-C. Franville, J. Am. Chem. Soc., 2002, 124, 14388.

108 P. N. Minoofar, B. S. Dunn and J. I. Zink, J. Am. Chem. Soc., $2005, \mathbf{1 2 7}, 2656$

109 H. Li, L. Fu, F. Liu, S. Wang and H. Zhang, New J. Chem., 2002, 26, 674 .

110 S. Li, H. Song, W. Li, X. Ren, S. Lu, G. Pan, L. Fan, H. Yu, H. Zhang, R. Qin, Q. Dai and T. Wang, J. Phys. Chem. B, 2006, 110, 23164.

111 E. Soini and I. Hemmilä, Clin. Chem., 1979, 25, 353.

112 Z. Y. Liu, M. Liu, W. L. Song, K. Pan, J. H. Li, Y. B. Bai and T. J. Li, Mater. Lett., 2006, 60, 1629.

113 X.-L. Chen, J.-L. Zou, T.-T. Zhao and Z.-B. Li, J. Fluoresc., 2007, 17, 235.

114 S. M. C. Sari, P. J. Debouttière, R. Lamartine, F. Vocanson, C. Dujardin, G. Ledoux, S. Roux, O. Tillement and P. Perriat, J. Mater. Chem., 2004, 14, 402.

115 K. Aslan, M. Wu, J. R. Lakowicz and C. D. Geddes, J. Am. Chem. Soc., 2007, 129, 1524.

116 B. Dubertret, P. Skourides, D. J. Norris, V. Noireaux, A. H. Brivanlou and A. Libchaber, Science, 2002, 298, 1759.

117 X. Michalet, F. F. Pinaud, L. A. Bentolila, J. M. Tsay, S. Doose, J. J. Li, G. Sundaresan, A. M. Wu, S. S. Gambhir and S. Weiss, Science, 2005, 307, 538 .

118 L. Dyadyusha, H. Yin, S. Jaiswal, T. Brown, J. J. Baumberg, F. P. Booy and T. Melvin, Chem. Commun., 2005, 25, 3201. 
119 C.-A. J. Lin, T. Liedl, R. A. Sperling, M. T. Fernández-Argüelles, J. M. Costa-Fernández, R. Pereiro, A. Sanz-Medel, W. H. Chang and W. J. Parak, J. Mater. Chem., 2007, 17, 1343.

120 C. Seydel, Science, 2003, 300, 80.

121 A. M. Derfus, W. C. W. Chan and S. N. Bhatia, Nano Lett., 2004, 4,11 .

122 A. E. Soini, A. Kuusisto, N. J. Meltola, E. Soini and L. Seveus, Microsc. Res. Tech., 2003, 62, 396.

123 P. R. Selvin, T. M. Rana and J. E. Hearst, J. Am. Chem. Soc., 1994, 116, 6029.

124 P. R. Selvin and J. E. Hearst, Proc. Natl. Acad. Sci. U. S. A., 1994, 91, 10024.

125 I. Hemmilä and V. Laitala, J. Fluoresc., 2005, 15, 559.

126 H. L. Handl and R. J. Gillies, Life Sci., 2005, 77, 361.

127 A. M. Adeyiga, P. M. Harlow, L. M. Vallarino and R. C. Leif, SPIE Proceedings Series 2678B-22, Optical Diagnosis of Living Cells and Biofluids, Advanced Techniques in Analytical Cytology, ed. D.L. Farkas, R.C. Leif, A.V. Priezzhev, T. Askura, B. Tromberg, A. Katzir, 1996, p. 1.

128 M. Xiao and P. R. Selvin, J. Am. Chem. Soc., 2001, 123, 7067.

129 DELFIA $\AA$ is a registered trademark of Wallac Oy.

130 G. Marriott, M. Heidecker, E. P. Diamandis and Y. YanMarriott, Biophys. J., 1994, 67, 957.

131 C. Picard, N. Geum, I. Nasso, B. Mestre, P. Tisnès, S. Laurent, R. N. Muller and L. V. Elst, Bioorg. Med. Chem. Lett., 2006, 16, 5309.

132 D. J. Qian, H. G. Liu, H. X. Huang, Q. Fu and X. S. Feng, Mater. Lett., 2001, 51, 525.

133 H. Härmä, T. Soukka, S. Lönnberg, J. Paukkunen, P. Tarkkinen and T. Lövgren, Luminescence, 2000, 15, 351.

134 V. Väisänen, H. Härmä, H. Lilja and A. Bjartell, Luminescence, $2000,15,389$

135 H. Härmä, T. Soukka and T. Lövgren, Clin. Chem., 2001, 47, 561.

136 Z. Ye, M. Tan, G. Wang and J. Yuan, Anal. Chem., 2004, 76, 513.

137 X. Hai, M. Tan, G. Wang, Z. Ye, J. Yuan and K. Matsumoto, Anal. Sci., 2004, 20, 245.

138 M. Tan, G. Wang, X. Hai, Z. Ye and J. Yuan, J. Mater. Chem., 2004, 14, 2896.

139 M. Tan, G. Wang, Z. Ye and J. Yuan, J. Lumin., 2006, 117, 20.

140 K. Aslan, M. Wu, J. R. Lakowicz and C. D. Geddes, J. Am. Chem. Soc., 2007, 129, 1524.

141 M. Tan, G. Wang, X. Hai, Z. Ye and J. Yuan, J. Mater. Chem., 2004, 14, 2896.

142 J. Feng, G. Shan, A. Maquieira, M. E. Koivunen, B. Guo, B. D. Hammock and I. M. Kennedy, Anal. Chem., 2003, 75, 5282.

143 D. Dosev, M. Nichkova, M. Liu, B. Guo, G.-Y. Liu, B. D. Hammock and I. M. Kennedy, J. Biomed. Opt., 2005, 5699, 473.

144 M. Nichkova, D. Dosev, S. J. Gee, B. D. Hammock and I. M. Kennedy, Anal. Chem., 2005, 77, 6864.

145 M. A. Flores-Gonzalez, C. Louis, R. Bazzi, G. Ledoux, K. Lebbou, S. Roux, P. Perriat and O. Tillement, Appl. Phys. A: Mater. Sci. Process., 2005, 81, 1385.

146 K. Lebbou, P. Perriat and O. Tillement, J. Nanosci. Nanotech., $2005,5,1448$.

147 E. Beaurepaire, V. Buissette, M.-P. Sauviat, D. Giaume, K. Lahlil, A. Mercuri, D. Casanova, A. Huignard, J.-L. Martin, T. Gacoin, J. P. Boilot and A. Alexandrou, Nano Lett., 2004, 4, 2079.

148 D. Giaume, V. Buissette, K. Lahlil, T. Gacoin, J.-P. Boilot, D. Casanova, E. Beaurepaire, M.-P. Sauviat and A. Alexandrou, Prog. Solid State Chem., 2005, 33, 99.

149 A. Doat, M. Fanjul, F. Pellé, E. Hollande and A. Lebugle, Biomaterials, 2003, 24, 3365.
150 F. Meiser, C. Cortez and F. Caruso, Angew. Chem., Int. Ed., 2004, 43, 5954.

151 F. C. van Veggel, J. W. Stouwdam, G. A. Hebbink and J. Huskens, Proc. SPIE-Int. Soc. Opt. Eng., 2003, 5224, 164.

152 Q. Masne-de-Chermont, C. Chanéac, J. Seguin, F. Pellé, S. Maîtrejean, J.-P. Jolivet, D. Gourier, M. Besodes and D. Scherman, Proc. Natl. Acad. Sci. U. S. A., 2007, 104, 9266.

153 F. Wang, Y. Zhang, X. Fan and M. Wang, Nanotechnology, 2006, 17,1527

154 B. A. Holm, E. J. Bergey, T. De, D. J. Rodman, R. Kapoor, L. Levy, C. S. Friend and P. N. Prasad, Mol. Cryst. Liq. Cryst, 2002, 374, 589.

155 S. Sivakumar, P. R. Diamente and F. C. J. M. van Veggel, Chem.Eur. J., 2006, 12, 5878.

156 D. Dosev, I. M. Kennedy, M. Godlewski, I. Gryczynski, K. Tomsia and E. M. Goldys, Appl. Phys. Lett., 2006, 88, 011906.

157 D. Dosev, M. Nichkova, R. K. Dumas, S. J. Gee, B. D. Hammock, K. Liu and I. M. Kennedy, Nanotechnology, 2007, 18, 055102.

158 S. Y. Yu, H. J. Zhang, J. B. Yu, C. Wang, L. N. Sun and W. D. Shi, Langmuir, 2007, 23, 7836

159 H. Lu, G. Yi, S. Zhao, D. Chen, L.-H. Guo and J. Cheng, J. Mater. Chem., 2004, 14, 1336.

160 S. Schultz, D. R. Smith, J. J. Mock and D. A. Schultz, Proc. Natl. Acad. Sci. U. S. A., 2000, 97, 996.

161 K. Aslan, M. Wu, J. R. Lakowicz and C. D. Geddes, J. Am. Chem. Soc., 2007, 129, 1524.

162 C. Sanchez, H. Arribart and M. M. G. Giraud-Guille, Nat. Mater., 2005, 4, 277.

163 C. Sanchez, B. Julian, P. Belleville and M. Popall, J. Mater. Chem., 2005, 15, 3559.

164 T. Itou and H. Matsuda, Key Eng. Mater., 1998, 67, 150.

165 G. Schottner, J. Kron and K. Deichmann, J. Sol-Gel Sci. Technol., 1998, 13, 183.

166 G. Schottner, Chem. Mater., 2001, 13, 3422.

167 M. Faloss, M. Canva, P. Georges, A. Brun, F. Chaput and J.-P. Boilot, Appl. Opt., 1997, 36, 6760.

168 B. Schaudel, C. Guermeur, C. Sanchez, K. Nakatani and J. Delaire, J. Mater. Chem., 1997, 7, 61.

169 B. Lebeau, C. Sanchez, S. Brasselet and J. Zyss, Chem. Mater., 1997, 9, 1012.

170 C. Rottman, G. Grader, Y. DeHazan, S. Melchior and D. Avnir, J. Am. Chem. Soc., 1999, 121, 8533.

171 T. D. de Morais, F. Chaput, J.-P. Boilot, K. Lahlil, B. Darracq and Y. Levy, Adv. Mater., 1999, 11, 107.

172 (a) D. Levy, J. M. S. Pena, C. J. Serna, J. M. Oton and L. Esquivias, J. Non-Cryst. Solids, 1992, 147-148, 646; (b) J. M. Oton, J. M. S. Pena, A. Serrano and D. Levy, Appl. Phys. Lett., 1995, 66, 929; (c) D. Levy and M. N. Armenise, in, Materials and Devices for Photonic Circuits, ed. L. G. Hubert-Pfalzgraf, S. I. Najafi, SPIE, Washington, 1999, vol. 3803, pp. 12-17; (d) D. Levy, Mol. Cryst. Liq. Cryst., 2000, 354, 159.

173 F. Pellé, S. Surblé, C. Serre, F. Millange and G. Férey, J. Lumin., 2007, 122, 492.

174 S. Surblé, C. Serre, F. Millange, F. Pellé and G. Férey, Solid State Sci., 2007, 9, 131

175 L. Cunha-Silva, L. Mafra, D. Ananias, L. D. Carlos, J. Rocha and F. A. Almeida Paz, Chem. Mater., 2007, 19, 3527.

176 F. N. Shi, L. Cunha-Silva, R. A. Sá Ferreira, L. Mafra, T. Trindade, L. D. Carlos, F. A. A. Paz and J. Rocha, J. Am. Chem. Soc., in press. 